\title{
Evaluation of Gridded and In Situ Precipitation Datasets on Modeled Glacio-Hydrologic Response of a Small Glacierized Himalayan Catchment
}

\author{
Louise Mimeau, Michel Esteves, Hans-Werner Jacobi, And IsAbella Zin \\ Institute for Geosciences and Environmental Research, University of Grenoble Alpes, CNRS, IRD, \\ Grenoble INP, Grenoble, France
}

(Manuscript received 27 July 2018, in final form 14 January 2019)

\begin{abstract}
Reliable precipitation data in the Himalayas are essential for the study of the water resources, the evolution of glaciers, and the present and future climate. Although several types of precipitation datasets are available for the Himalayan region, all of them have limitations, which hamper the quantification of the precipitation fluxes at high elevations. This study compares different types of precipitation datasets issued from (i) in situ data, (ii) satellite-based data [TRMM, Climate Hazards Group Infrared Precipitation with Station Data (CHIRPS)], and (iii) a reanalysis product [High Asia Refined analysis (HAR)] for a small headwater catchment at high elevations (Upper Dudh Koshi, Nepal) and assesses the impact of the precipitation uncertainty on the result of the modeling of the glacio-hydrological system. During the analyzed period from 2010 to 2015, large differences between the precipitation datasets occur regarding annual amounts (ranging from 410 to $1190 \mathrm{~mm} \mathrm{yr}^{-1}$ ) as well as in seasonal and diurnal cycles. The simulations with the glacio-hydrological model Distributed Hydrological Soil Vegetation Model-Glaciers Dynamics Model (DHSVM-GDM) show that the choice of a given precipitation dataset greatly impacts the simulated snow cover dynamics and glacier mass balances as well as the annual, seasonal, and diurnal streamflows. Due to the uncertainty in the precipitation, the simulated contribution of the ice melt to the annual outflow also remains uncertain and simulated fractions range from $29 \%$ to $76 \%$ for the $2012-13$ glaciological year.
\end{abstract}

\section{Introduction}

The Hindu Kush Himalaya (HKH) holds the third largest glacierized area after the polar regions and provides water for more than 1.5 billion inhabitants living in the major Asian basins of the Ganges, Brahmaputra, Indus, Yellow River, and Yangtze (Immerzeel et al. 2010). The HKH is a key region to study both climate and water resources availability as its mountain glaciers play an important role in the water cycle (Viviroli et al. 2007; Kaser et al. 2010; Pritchard 2017) and are a good indicator of climate change (Scherler et al. 2011; Bolch et al. 2012; Kääb et al. 2015). Moreover, this densely populated region is very vulnerable concerning the access to water (Shrestha and Aryal 2011; McDowell et al. 2013; Singh et al. 2016). Knowledge of the precipitation fluxes occurring in the HKH is essential for the study of present climate and hydrological regimes and their future evolution in order to develop

\footnotetext{
Corresponding author: Michel Esteves, michel.esteves@ird.fr
}

appropriate adaptation strategies for water resources management.

Precipitation in the HKH region is influenced by two major synoptical situations: the summer Indian monsoon system, which starts in the Bay of Bengal and progresses toward the Himalayan mountain range, bringing heavy precipitation between June and September, and the westerlies originating from the Mediterranean, Arabian, or Caspian Seas and bringing precipitation during winter (Lang and Barros 2004; Wang 2006; Bookhagen and Burbank 2010). However, at high elevations, due to the complex topography, the atmospheric processes remain poorly understood. In addition, the quantification of the precipitation involves large uncertainties because of limited observations. Particularly, the relation between precipitation and elevation and the distribution of the precipitation phase (rainfall and snowfall) is not yet fully resolved (Ménégoz et al. 2013; Cannon et al. 2017).

Nevertheless, several types of precipitation datasets are available for the HKH region. First, some in situ measurements exist and are often used as reference 
data, however, the meteorological stations measuring precipitation are scarce with relatively short time series and very few observations at elevations above $5000 \mathrm{~m}$ MSL. Moreover instruments for in situ measurements are known for underestimating the solid precipitation (Wolff et al. 2015). Thus, a reliable relationship between precipitation and elevation is difficult to realize. In the Dudh Koshi basin Salerno et al. (2015) established an exponentially decreasing precipitation gradient, while Eeckman et al. (2017) proposed linear gradients with elevation thresholds. As a result, large uncertainties concerning the spatial distribution of the precipitation exist. Furthermore, gridded precipitation products are available such as TRMM based on satellite measurements (Bookhagen and Burbank 2006), APHRODITE based on a spatial interpolation of a rain gauge network (Yatagai et al. 2012), and reanalysis datasets like ERA40 (Uppala et al. 2005), ERA-Interim (Dee et al. 2011), MERRA (Rienecker et al. 2011), and NCEP-NCAR (Kalnay et al. 1996). The gridded datasets provide a full spatial coverage, but are only available at coarse spatial $\left(>0.25^{\circ}\right)$ and temporal (mostly daily) resolutions. Moreover, satellite products such as TRMM are also known for showing significant biases for solid precipitation (Ménégoz et al. 2013; Maussion et al. 2014). Nevertheless, these datasets are commonly used at different spatial and time scales in the HKH region in climatological, glaciological, and hydrological studies, which all depend strongly on precipitation data.

Several studies have compared the different precipitation datasets over the HKH region (Andermann et al. 2011; Palazzi et al. 2013; Ceglar et al. 2017) and showed high discrepancies in the annual amounts as well as in the seasonal variability. In contrast, the precipitation uncertainty at very high elevation and at subdaily time scales has not been addressed in these studies. Yet, the estimation of precipitation at small spatial and temporal scale is important for the understanding of glaciological or hydrological processes in these areas. For instance, in glaciological modeling the amount of precipitation and its spatial distribution on glaciers determine the accumulation and plays an important role in the glacier mass balance estimation (Immerzeel et al. 2012; Jarosch et al. 2012).

This study evaluates the precipitation uncertainty in a small high elevated catchment (above $4000 \mathrm{~m}$ MSL) located in the Dudh Koshi catchment in Nepal. Five in situ and gridded precipitation datasets available for the period 2010-15 at high spatial resolution $\left(<0.25^{\circ}\right)$ and temporal resolution (from hourly to daily) were used for comparison. Among them two precipitation datasets derived from two different types of rain gauges: classical tipping buckets and Geonor gauges, which are designed for measuring solid precipitation. Due to the scarcity of in situ data in the Nepalese Himalaya, precipitation data measured with tipping buckets are often used in hydrological and glaciological studies in high elevated catchments (Immerzeel et al. 2014; Ragettli et al. 2015; Salerno et al. 2015; Shea et al. 2015; Soncini et al. 2016). This study evaluates the uncertainty of in situ measurements in a catchment that receives a significant share of its annual precipitation as snow.

This study compares the precipitation derived from each dataset on annual, monthly, and subdaily time scales in order to assess the temporal variations and the liquid and solid phases of the precipitation. Moreover, the uncertainty of the interpolation method used for spatializing in situ data is addressed by estimating different sets of precipitation and temperature altitudinal gradients and analyzing their impact on the average basin precipitation and the snowfall/rainfall distribution. In the second part of this study, the glacio-hydrological model Distributed Hydrological Soil Vegetation Model-Glaciers Dynamics Model (DHSVM-GDM) is used to evaluate the impact of the precipitation uncertainty on the simulated water balance and the estimated contributions of ice and snowmelt to the outflow. Finally, the simulated results of the outflow, the snow cover, as well as the glacier mass balances are compared for the different precipitation datasets at annual to diurnal time scales.

\section{Study area}

This study focuses on the Pheriche subcatchment of the Dudh Koshi basin (outlet at coordinates $27.89^{\circ} \mathrm{N}$, $86.82^{\circ} \mathrm{E}$ ) located in Nepal on the southern slopes of Mt. Everest in the Sagarmatha National Park (SNP; Fig. 1). The catchment area corresponds to $146 \mathrm{~km}^{2}$, and its elevation extends from 4260 to 8848 m MSL. Further details can be found in Mimeau et al. (2018).

Figure 1c shows the precipitation as a function of elevation in the upper Dudh Koshi basin. Mean annual precipitation estimated for the period $2000-15$ was derived from in situ data collected at meteorological stations maintained by the EvK2-CNR association (www.evk2cnr.org) and from the PAPRIKA-PRESHINE database (Chevallier et al. 2017). The figure confirms the decrease of the annual precipitation above $2500 \mathrm{~m}$ MSL in the Dudh Koshi catchment (Savéan et al. 2015; Salerno et al. 2015; Eeckman et al. 2017). Yet, around $80 \%$ of the Pheriche catchment is situated above $5000 \mathrm{~m}$ MSL, and the highest precipitation gauge in the Khumbu region is the Pyramid located at $5035 \mathrm{~m}$ MSL, which shows the lack of in situ measurements for the 

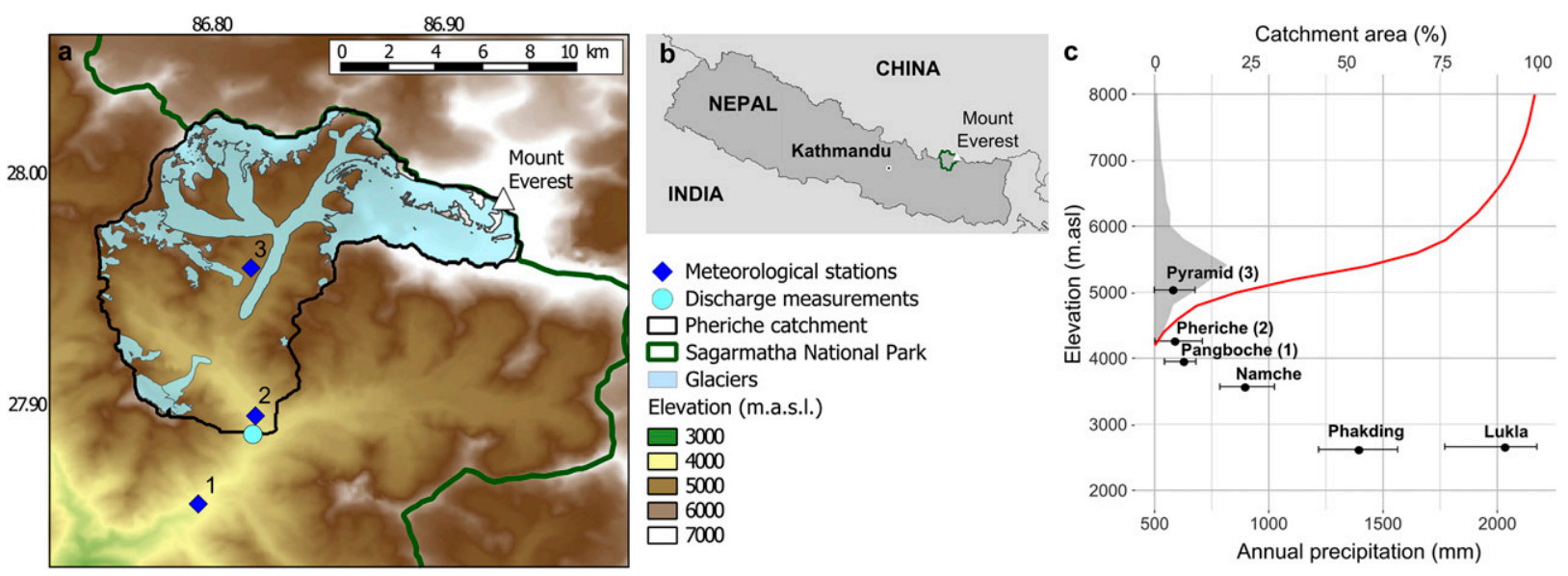

FIG. 1. (a),(b) Study area: Pheriche catchment (black) in the Sagarmatha National Park (green) in Nepal. Numbers correspond to the meteorological stations listed in Table 1. (c) Observed mean annual precipitation as a function of elevation. Annual precipitation is calculated for the period 2010-15 for years with data coverage above $90 \%$ (data measured with tipping bucket rain gauges). The hypsometry of the Pheriche basin is represented in gray and cumulative hypsometry by the red line.

analysis of the spatial variability of precipitation in the Pheriche catchment.

\section{Data and method}

\section{a. Available datasets}

In situ meteorological data are available at hourly time steps at the three meteorological stations located in Pangboche (3950 m MSL), Pheriche (4260 m MSL), and Pyramid (5035 m MSL; Table 1). At the Pheriche and Pyramid stations, precipitation was measured with two different types of rain gauges: classical tipping buckets and Geonor T-200 sensors (since December 2012). Classical tipping buckets are known for not correctly measuring solid precipitation (Wolff et al. 2015). The Geonor rain gauges are designed to measure solid precipitation more accurately, however a correction still needs to be applied on the measured data for potential undercatch. In both locations most of the time the wind speed is lower than $3.2 \mathrm{~m} \mathrm{~s}^{-1}$ (third quartile) at Pyramid and $3.0 \mathrm{~m} \mathrm{~s}^{-1}$ (third quartile) at Pheriche, median values were 2.00 and $1.42 \mathrm{~m} . \mathrm{s}^{-1}$, respectively. For this range of values, the catch efficiency for snowfall of a Geonor T-200B equipped with a single Alter wind shield could be only $65 \%$ (Wolff et al. 2015, their Fig. 5). Accurate measurement of snow also depends on the type of snowflake observed during a snowfall (Thériault et al. 2012). Geonor raw data were corrected from bias using a dynamic correction model, based on air temperature, wind speed and precipitation phase. The correction coefficients were estimated as described in Førland et al. (1996). For this study, two precipitation datasets were established based on the measurements with the two instruments referred as Pluvio and Geonor datasets.

Three other precipitation datasets available at high spatial resolution $(<30 \mathrm{~km})$ and daily or subdaily time scale for the Himalayan region were used (Table 2). We considered the High Asia Refined analysis (HAR) atmospheric dataset, which was generated by dynamical downscaling of global analysis data using the Weather Research and Forecasting (WRF) Model and provides data at an hourly time step and a resolution of $10 \mathrm{~km}$ over the Tibetan Plateau from 2001 to 2014 (Maussion et al. 2014). We further used precipitation data from the Tropical Rainfall Measuring Mission (TRMM) Multisatellite Precipitation Analysis (TMPA). This study makes use of the TRMM 3B42 version 7 product, which provides precipitation data from a combination of remote sensing observations (microwave imager, precipitation radar, visible and infrared scanner) and in situ

TABLE 1. List of meteorological stations with observed variables and rain gauge types. Definitions are as follows: $T$ is air temperature, $P$ is precipitation, WS is wind speed, RH is relative humidity, SWin is incoming shortwave radiation, and LWin is incoming longwave radiation; TB is tipping bucket, and Geonor is the Geonor T-200 sensor.

\begin{tabular}{clccccc}
\hline \hline No. & Name & Elevation $(\mathrm{m})$ & Lat $\left({ }^{\circ} \mathrm{N}\right)$ & Lon $\left({ }^{\circ} \mathrm{E}\right)$ & Observed variables & Type of rain gauge \\
\hline 1 & Pangboche & 3950 & 27.857 & 86.794 & $T, P$ & TB \\
2 & Pheriche & 4260 & 27.895 & 86.819 & $T, P, \mathrm{WS}, \mathrm{RH}$, SWin & TB, Geonor \\
3 & Pyramide & 5035 & 27.959 & 86.813 & $T, P, \mathrm{WS}, \mathrm{RH}$, SWin, LWin & TB, Geonor \\
\hline
\end{tabular}


TABLE 2. List of precipitation datasets. Definitions are as follows: PR gradient is precipitation gradient, $\mathrm{T}$ gradient is temperature gradient, $\mathrm{H}$ is hourly, $\mathrm{D}$ is daily, $\mathrm{M}$ is monthly, $\mathrm{A}$ is annual, and $\mathrm{B}$ is benchmark.

\begin{tabular}{lcccccc}
\hline \hline \multicolumn{1}{c}{ Dataset } & Spatial resolution & Temporal resolution & Time period & PR gradient & T gradient & Reference \\
\hline Geonor (in situ) & 2 stations & Hourly & $2012-15$ & H, D, M, A, B & H, D, M, A, B & This study (IRD) \\
Pluvio (in situ) & 2 stations & Hourly & $2010-15$ & H & D & This study (EvK2-CNR) \\
CHIRPS 1 & $5 \mathrm{~km}$ & Daily & $2010-15$ & - & D & Funk et al. (2015) \\
CHIRPS 2 & $5 \mathrm{~km}$ & Hourly & $2012-15$ & - & D & Funk et al. (2015) \\
HAR & $10 \mathrm{~km}$ & Hourly & $2010-14$ & - & D & Maussion et al. (2014) \\
TRMM & $27 \mathrm{~km}$ & $3 \mathrm{~h}$ & $2010-15$ & - & D & Huffman et al. (2007) \\
\hline
\end{tabular}

observations (Huffman et al. 2007). The TRMM precipitation data are available since 1998 at a spatial resolution of $0.25^{\circ}$ and a time step of $3 \mathrm{~h}$. Finally, we used the Climate Hazards Group Infrared Precipitation with Station Data (CHIRPS) precipitation product (Funk et al. 2015). CHIRPS is a global precipitation dataset, which combines satellite imagery (infrared cold cloud duration observations) with in situ stations data. CHIRPS precipitation data are available since 1981 at a daily time step and a spatial resolution of $0.05^{\circ}$.

Due to the mismatch between the spatial resolutions of the three gridded datasets, particularly TRMM $(30 \mathrm{~km})$ and HAR $(10 \mathrm{~km})$, and the catchment area $\left(146 \mathrm{~km}^{2}\right)$, we do not intend in this study to evaluate the quality of the datasets for the Pheriche catchment, but to assess the error on the precipitation for a small Himalayan catchment and to quantify the uncertainty of the simulated hydrological response to a realistic range of forcing precipitation.

\section{1) Hourly DOWNSCALING}

Since the hydrological model is forced with precipitation data at a $1 \mathrm{~h}$ time step, the TRMM and CHIRPS datasets were converted into hourly data.

In the case of the TRMM dataset, the precipitation over $3 \mathrm{~h}$ was uniformly distributed among the $1 \mathrm{~h}$ time step.

Concerning CHIRPS precipitation, two different datasets were established in order to assess the impact of the subdaily distribution of the precipitation on the repartition between solid and liquid phases and on the glacio-hydrological modeling. First, a dataset referred to as CHIRPS 1 was derived by uniformly distributing the precipitation intensity over the entire day. The second dataset, CHIRPS 2, was created using the precipitation intensity observed by the Geonor rain gauges according to

$$
P_{\text {CHIRPS } H}=P_{\text {ChIRPS } J} \times \frac{P_{\mathrm{Obs} H}}{P_{\mathrm{Obs} J}},
$$

where $P_{\text {CHIRPSH }}$ and $P_{\text {CHIRPS } J}$ are the $1 \mathrm{~h}$ and $24 \mathrm{~h}$ precipitation in a CHIRPS grid cell and $P_{\mathrm{Obs} H}$ and $P_{\mathrm{Obs} J}$ are the $1 \mathrm{~h}$ and $24 \mathrm{~h}$ precipitation measured by the closest
Geonor rain gauge. If no precipitation was measured during a day $\left(P_{\mathrm{Obs} J}=0\right)$, the CHIRPS daily precipitation was also uniformly distributed over the entire day.

\section{2) SPATIAL INTERPOLATION}

To estimate the Pheriche catchment precipitation from the Geonor and Pluvio datasets, the Pheriche and Pyramid gauges were spatially interpolated by inverse distance weighting (IDW) at a 100-m resolution over the catchment and an hourly altitudinal precipitation gradient was applied in order to take into account the topography (see section 4). The HAR, TRMM, CHIRPS 1, and CHIRPS 2 catchment precipitation were estimated by calculating the weighted average of the datasets grid cells overlapping the catchment domain.

\section{3) SEPARATiOn of THE PRECiPITATION PHASES}

The same temperature distribution was used to separate solid and liquid phases or every precipitation dataset. The temperature distribution is derived from the Pheriche and Pyramid AWS in situ measurements which were interpolated by IDW at $100-\mathrm{m}$ resolution. A daily temperature lapse rate (see section 4) was also applied to take into account the elevation. Precipitation is defined as snowfall if the temperature is below $0^{\circ} \mathrm{C}$ and as rainfall if the temperature is above $2^{\circ} \mathrm{C}$. Between $0^{\circ}$ and $2^{\circ} \mathrm{C}$ precipitation is composed of mixed snowfall with the share of rainfall increasing linearly with temperature.

\section{4) Altitudinal gRadients}

The precipitation and temperature lapse rates are calculated using in situ data collected at Pangboche (3950 m MSL), Pheriche (4260 m MSL), and Pyramid (5035 m MSL). We analyzed the impact of the imposed temperature and precipitation lapse rates on the catchment precipitation and on the snow and rainfall partitioning by testing different sets of gradients calculated at hourly, daily, monthly, and annual time scales. A benchmark set of lapse rates with a constant precipitation lapse rate equal to 0 and a standard average temperature gradient equal to $-0.0065^{\circ} \mathrm{Cm}^{-1}$ (Barry and Chorley 2009) was used as reference. To retain only significant hourly and daily precipitation 
lapse rates, the lapse rate is set to zero in cases where the lapse rates between the two pairs of stations (Pangboche-Pheriche and Pheriche-Pyramid) were not of the same sign.

\section{b. Hydro-glaciological modeling}

\section{1) NUMERICAL SETUP}

Glacio-hydrological simulations are run with DHSVMGDM, a physically based and spatially distributed developed by Wigmosta et al. (1994) and Naz et al. (2014) is a model. The parameterization of snow and glaciers in DHSVM-GDM was modified concerning the snow albedo, the snow transport by avalanches, and the ice melting for debris-covered glaciers. These modifications as well as the applied model parameters are presented in detail in Mimeau et al. (2018).

To describe the topography of the study area an ASTER DEM originally at $30-\mathrm{m}$ resolution was resampled to a $100-\mathrm{m}$ resolution. Data used for the soils, land cover, and glacier description are described in (Mimeau et al. 2018).

Concerning the meteorological forcing, in situ measurements of air temperature, relative humidity, wind speed, incoming shortwave and incoming longwave from the Pheriche and Pyramid AWS were spatially distributed using the IDW method. To test the sensitivity of the glacio-hydrological modeling to the temperature and precipitation gradients the model was forced with the Geonor precipitation dataset with five sets of precipitation and temperature gradients: hourly, daily, monthly, annual, and benchmark gradients (Table 2).

For the Geonor and Pluvio datasets, hourly precipitation gradients are used to derive the spatially resolved precipitation. For the HAR, TRMM, and CHIRPS datasets, no precipitation gradient was applied and the precipitation was uniformly distributed over the original grid of each dataset. Concerning temperatures, the same daily temperature lapse rates were applied for the six simulations.

Simulations were run at a 1-h time step and 100-m spatial resolution for periods with available meteorological, precipitation, and discharge data.

\section{2) Model evaluation}

A multicriteria evaluation was performed using the simulated outflows, the snow cover area, and the glacier mass balance. Discharge measurements of the Khumbu River at Pheriche station were used as reference for the evaluation of simulated outflows. Discharge measurements were obtained from a pressure water level sensor at a 1-h interval since October 2010 with an uncertainty of $15 \%$. Nash-Sutcliffe efficiency
(NSE; Nash and Sutcliffe 1970) and Kling-Gupta efficiency (KGE; Gupta et al. 2009) were chosen as objective functions and applied to daily discharges. We used daily MODIS satellite images corrected and resampled at a 250-m resolution with the MODImLab algorithm (Sirguey et al. 2009) to evaluate the simulation of the snow cover area (Mimeau et al. 2018). The simulated glacier mass balances were evaluated at basin scale by comparison with previously published regional geodetic mass balances.

\section{Results and discussion}

\section{a. Temperature and precipitation gradients}

Figure 2 presents the calculated hourly, daily, monthly, and annual temperature and precipitation lapse rates and the associated correlation coefficient $R^{2}$. The mean annual temperature lapse rate in the Pheriche catchment is $-5.1^{\circ} \mathrm{C}(1000 \mathrm{~m})^{-1}$. The temperature gradient is smallest during the winter and monsoon seasons and highest during the premonsoon and postmonsoon seasons. These gradients are consistent with the results by Kattel et al. (2013) and Immerzeel et al. (2014), who found mean annual gradients of $-5.2^{\circ}$ and $-5.4^{\circ} \mathrm{C}$ $(1000 \mathrm{~m})^{-1}$, respectively, and similar seasonal patterns for the southern slope of the central Himalayas and in the Langtang basin. During the period from November 2010 to November 2015 we found 25 days with positive daily temperature gradients. Such temperature inversions are only represented by hourly and daily gradients, while monthly and annual gradients do not capture such rare conditions.

For the precipitation lapse rates, we found a mean annual lapse rate of $35 \mathrm{~mm}(1000 \mathrm{~m})^{-1}$, which is consistent with the results by Salerno et al. (2015) and Eeckman et al. (2017), who found slightly decreasing annual precipitation above $4000 \mathrm{~m}$ MSL. However, at monthly, daily and hourly scales we found fluctuations between positive and negative lapse rates. The monthly lapse rates show positive values in winter (between January and April) and mainly negative values during the monsoon and postmonsoon seasons. This corresponds to the different types of precipitation fluxes occurring in the catchment: during the monsoon season the precipitation flux has a south-north direction and decreases with altitude after reaching a maximum precipitation between 2500 and $3000 \mathrm{~m}$ MSL (Salerno et al. 2015; Savéan et al. 2015; Eeckman et al. 2017). However, in winter the precipitation are caused by the westerlies with a west-east gradient, which can contribute to more precipitation at higher altitudes. Figure $2 \mathrm{~b}$ shows that at the hourly time step (i.e., the time step of the hydrological modeling in this study), 


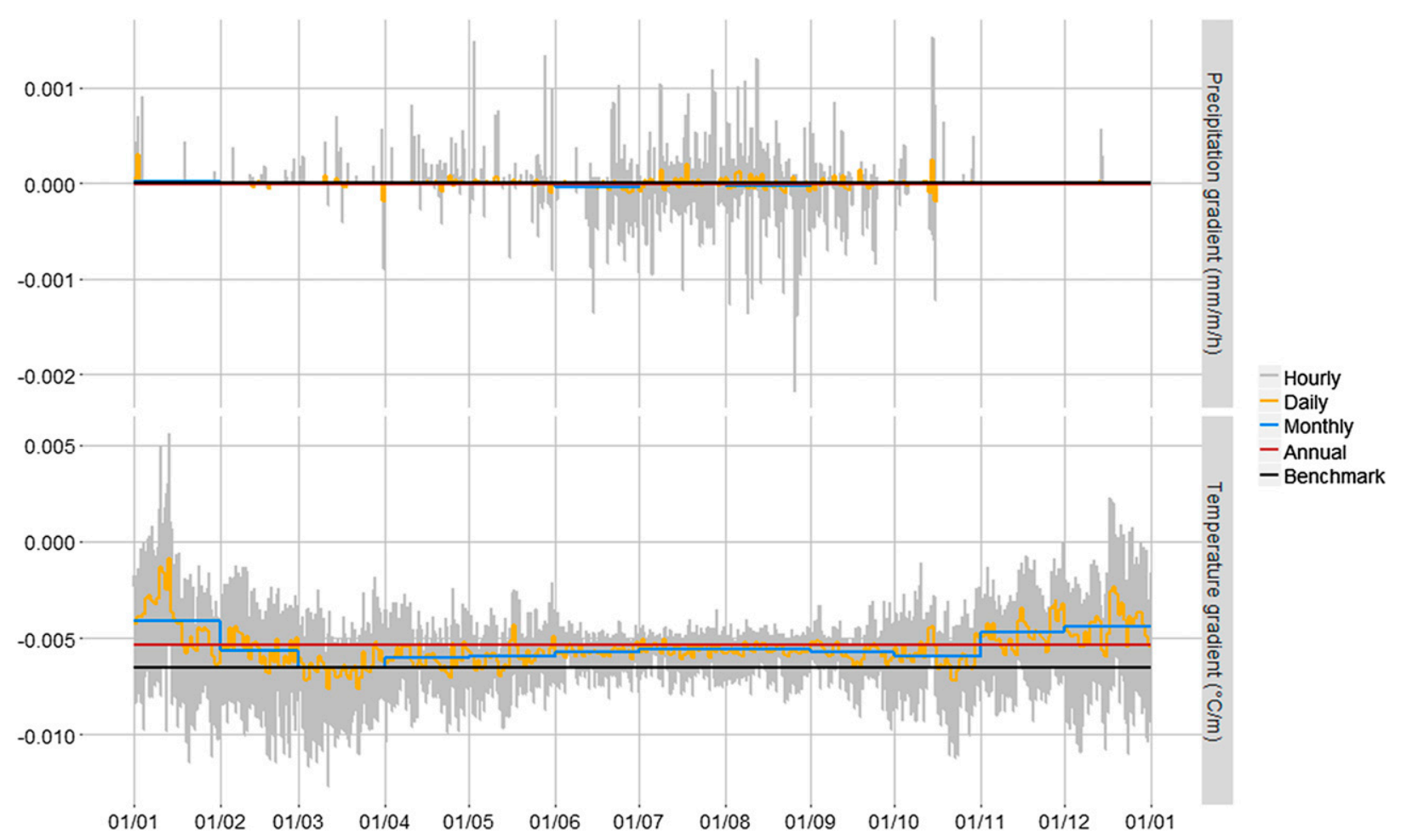

FIG. 2. (a) Temperature and (b) precipitation gradients calculated at hourly, daily, monthly, and annual time steps with in situ data (Pyramid, Pheriche, and Pangboche stations).

the hourly precipitation gradient show large fluctuations whereas the annual and monthly gradients are very close to the benchmark gradient equal to zero.

\section{b. Precipitation datasets analysis}

\section{1) ANNUAl PRECIPITATION AMOUNTS}

The six analyzed precipitation datasets show a large variability of annual precipitation amount over the Pheriche catchment (Table 3). The Pluvio and HAR datasets indicate less than $470 \mathrm{~mm} \mathrm{yr}^{-1}$ of precipitation, whereas the CHIRPS and TRMM datasets result in precipitation rates higher than $960 \mathrm{~mm} \mathrm{yr}^{-1}$. The Geonor dataset gives an intermediate rate with $688 \mathrm{~mm} \mathrm{yr}^{-1}$. The distribution between solid and liquid precipitation varies between the datasets with the fraction of annual solid precipitation ranging from $60 \%$ for the TRMM dataset to $76 \%$ for HAR. A large difference between the two datasets from the in situ measurements is found $[242 \mathrm{~mm}$ (59\%) of annual snowfall for the Pluvio dataset versus $533 \mathrm{~mm}(78 \%)$ for the Geonor dataset] related to the undercatch of the solid precipitation by the standard

TABLE 3. Mean annual basin precipitation obtained with the six precipitation datasets during the period 2010-15 (depending on data availability) and the glaciological year 2012-13. The HAR, CHIRPS 1, CHIRPS 2, and TRMM total precipitation were derived from the weighted average of the datasets grid cells overlapping the catchment domain (see section 2).

\begin{tabular}{|c|c|c|c|c|c|c|}
\hline Dataset & Geonor & Pluvio & CHIRPS 1 & CHIRPS 2 & HAR & TRMM \\
\hline Period & $2012-15$ & $2010-15$ & $2010-15$ & $2012-15$ & 2010-14 & 2010-15 \\
\hline Total (mm) & 687 & 409 & 1065 & 961 & 471 & 1186 \\
\hline Monsoon (\%) & 58 & 84 & 76 & 77 & 53 & 75 \\
\hline Snowfall (mm) & 533 & 242 & 638 & 627 & 359 & 707 \\
\hline \multirow[t]{2}{*}{ Snowfall (\%) } & 78 & 59 & 60 & 65 & 76 & 60 \\
\hline & \multicolumn{6}{|c|}{$2012-13$} \\
\hline Total (mm) & 711 & 429 & 1005 & 1011 & 521 & 1235 \\
\hline Monsoon (\%) & 58 & 74 & 73 & 73 & 38 & 67 \\
\hline Snowfall (mm) & 516 & 240 & 578 & 612 & 406 & 687 \\
\hline Snowfall (\%) & 73 & 56 & 57 & 61 & 77 & 56 \\
\hline
\end{tabular}


TABLE 4. Mean annual basin precipitation during the period 2012-15 obtained with the Geonor precipitation dataset and with temperature and precipitation lapse rates calculated at different time steps.

\begin{tabular}{lrrrrc}
\hline \hline \multicolumn{1}{c}{ Lapse rate } & Hourly & Daily & Monthly & Annual & Benchmark \\
\hline Total (mm) & 645 & 600 & 575 & 588 & 597 \\
Monsoon (\%) & 58 & 57 & 55 & 59 & 59 \\
Snowfall (mm) & 488 & 451 & 433 & 436 & 464 \\
Snowfall (\%) & 76 & 75 & 75 & 74 & 78 \\
\hline
\end{tabular}

pluviometer. The two CHIRPS datasets result in rather similar annual precipitation for the year 2012-13, however, the CHIRPS 2 dataset results in a slightly larger fraction of snowfall compared to CHIRPS 1 with fractions of $61 \%$ and $57 \%$ of solid precipitation.

We also compared the rainfall and snowfall data from the HAR dataset in the Pheriche catchment for the period 2010-14 and found a higher snowfall fraction (83\%). The large fraction of solid precipitation with the HAR dataset compared to the other datasets corroborates other studies finding that WRF with the Thompson microphysics scheme tends to produce too much snowfall (e.g., Hughes et al. 2017).

We tested the impact of the temperature thresholds on the rainfall/snowfall repartition by changing the thresholds to $-1^{\circ}$ and $3^{\circ} \mathrm{C}$, which are also reliable thresholds according to the existing literature (e.g., L'hôte et al. 2005; Froidurot et al. 2014; Jennings et al. 2018), and found similar snowfall fractions for every datasets.

Concerning the impact of the lapse rate on the catchment precipitation, Table 4 shows that the derived annual amounts range between 575 and $645 \mathrm{~mm}$ for the Geonor dataset. Therefore, the uncertainty related to the lapse rate is small compared to the uncertainty related to the source of the precipitation data. Nevertheless, the lapse rates impact the estimation of very high altitude precipitation (above $6000 \mathrm{~m}$ MSL) and, thus, mainly impact the amount of annual solid precipitation ranging from 433 to $488 \mathrm{~mm}$. The application of the hourly lapse rate results in the highest precipitation because positive lapse rates mainly occur during the winter season, which leads to larger amounts of snowfall at very high altitudes. On the opposite, the monthly and annual lapse rates give smaller precipitation amounts than the benchmark dataset. Applying the monthly and annual gradients causes a decrease at higher altitudes, while the precipitation is homogeneous in the benchmark dataset.

We also tested the sensitivity of the temperature and precipitation lapse rates separately. The results show that the solid/liquid precipitation distribution is mainly sensitive to the precipitation lapse rate. The chosen time step for the temperature lapse rate calculation has a limited impact on the solid/liquid precipitation distribution as the mean annual snowfall amount obtained with the hourly, daily, monthly, and annual temperature lapse rates tested separately ranges between 525 and $533 \mathrm{~mm}$.

Figure 3 presents the spatial distribution of the precipitation for each dataset for the glaciological year 2012-13, which is the only common year in all datasets. The precipitation datasets show a large variability in their spatial distribution. The interpolated in situ precipitation

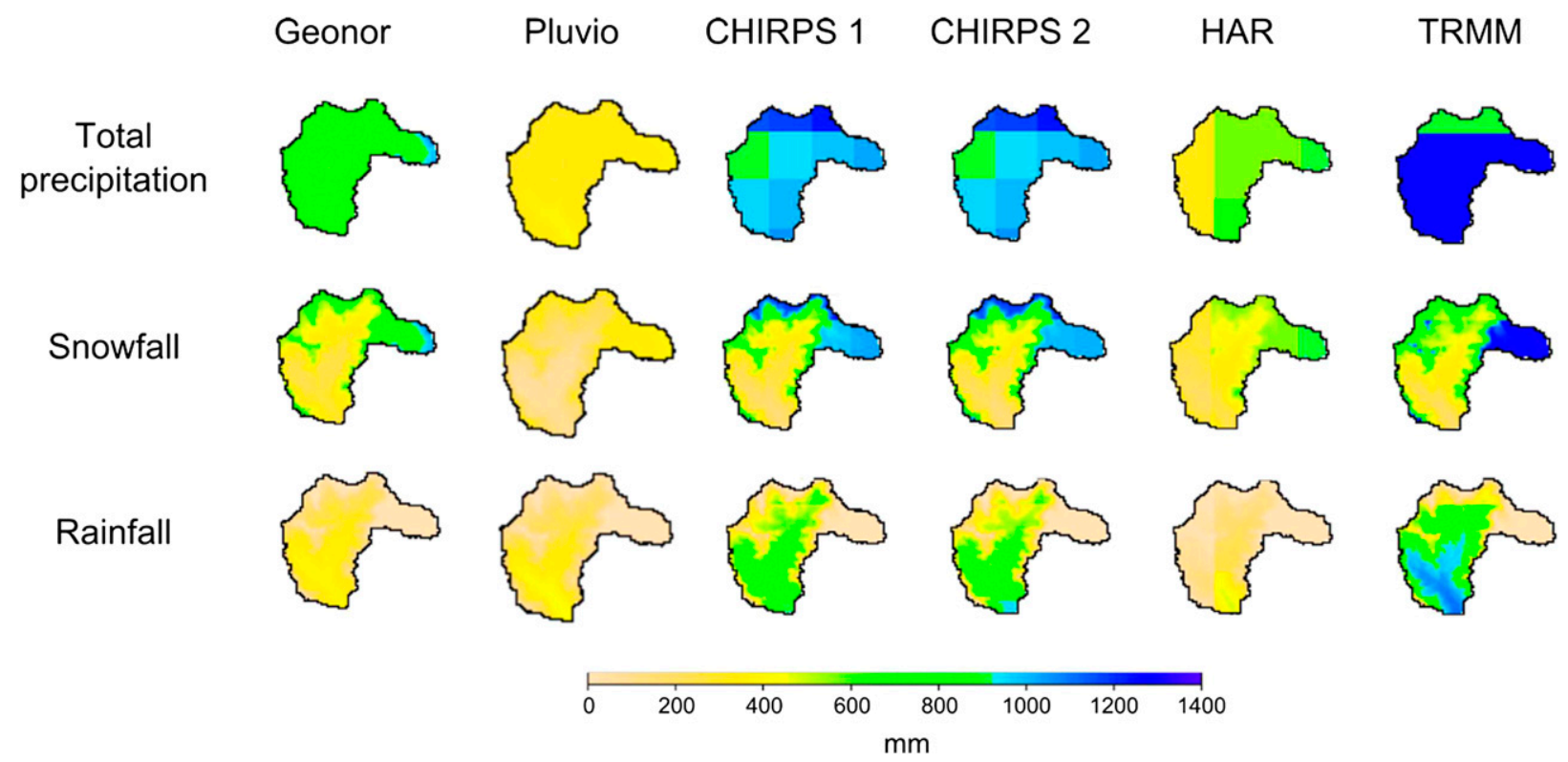

FIG. 3. Spatial distribution of the total precipitation, snowfall, and rainfall for the year 2012-13 for each precipitation dataset. 


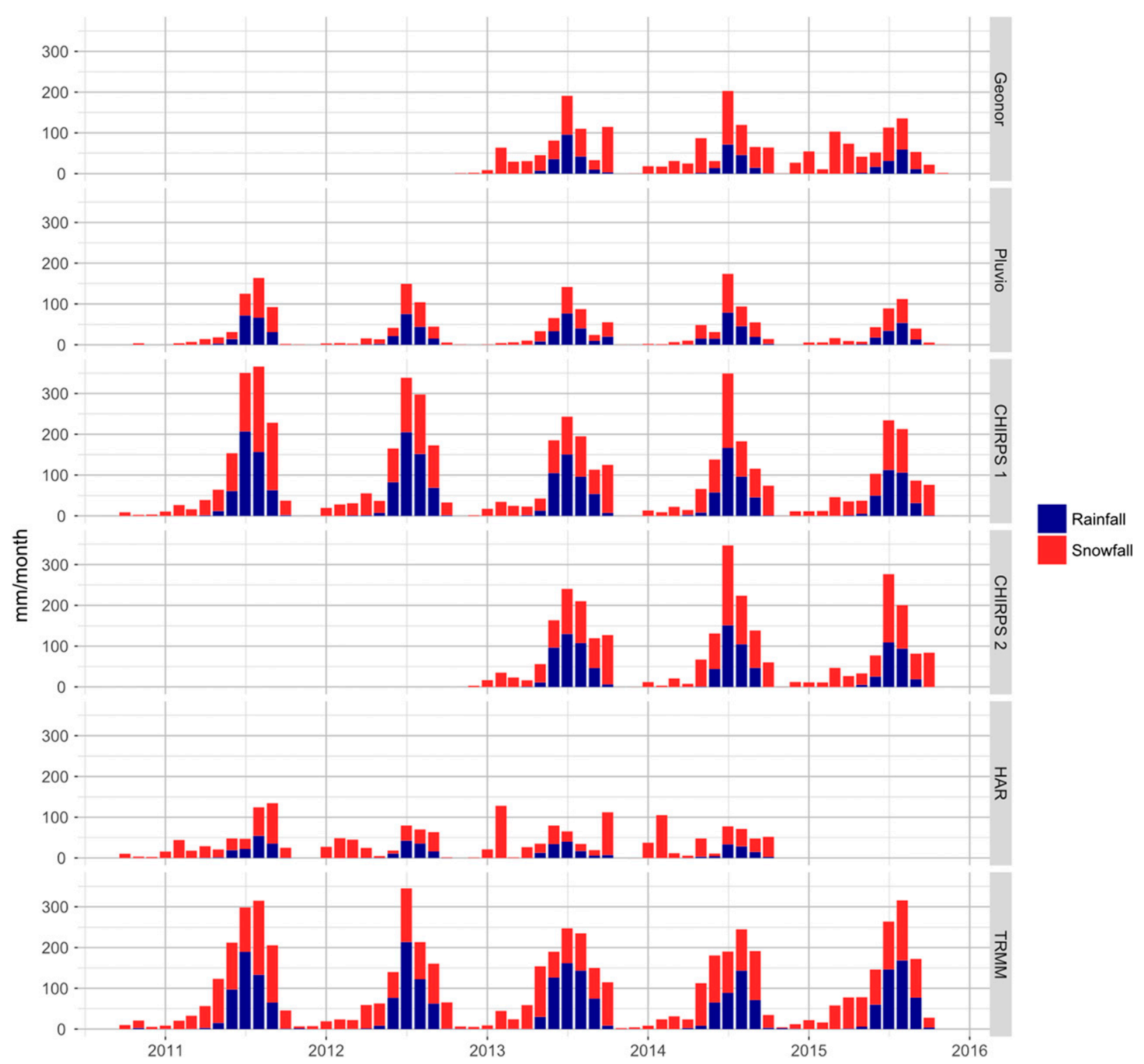

FIG. 4. Monthly rainfall and snowfall derived for each dataset.

results in a relatively uniform precipitation over the catchment with more snowfall at higher altitudes, especially in the Eastern part of the catchment around the Mount Everest. The Geonor and Pluvio datasets have similar rainfall but different snowfall patterns. The CHIRPS datasets show a south-north gradient with more precipitation on the northern part of the catchment and a west-east gradient. The CHIRPS 1 dataset shows more rainfall in the valleys and less snowfall on elevated areas compared to CHIRPS 2. The HAR precipitation also follows a strong west-east gradient with very little precipitation on the western part (less than $300 \mathrm{~mm}$ ) and more than $800 \mathrm{~mm}$ on the eastern part around Mt. Everest. Since TRMM precipitation has a coarse spatial resolution, the catchment is almost entirely covered by one grid cell leading to a uniform precipitation pattern for the catchment. The grid cell corresponding to the northern part of the catchment gives a smaller amount of precipitation, since it is centered on the Tibetan plateau, which receives much less precipitation and is not representative for the Pheriche catchment.

\section{2) SEAsonal VARIATION OF THE PRECIPITATION}

Figure 4 represents the monthly precipitation for each precipitation dataset between 2011 and 2015. The Pluvio dataset leads to different seasonal distribution of the precipitation compared to the Geonor dataset with $84 \%$ 


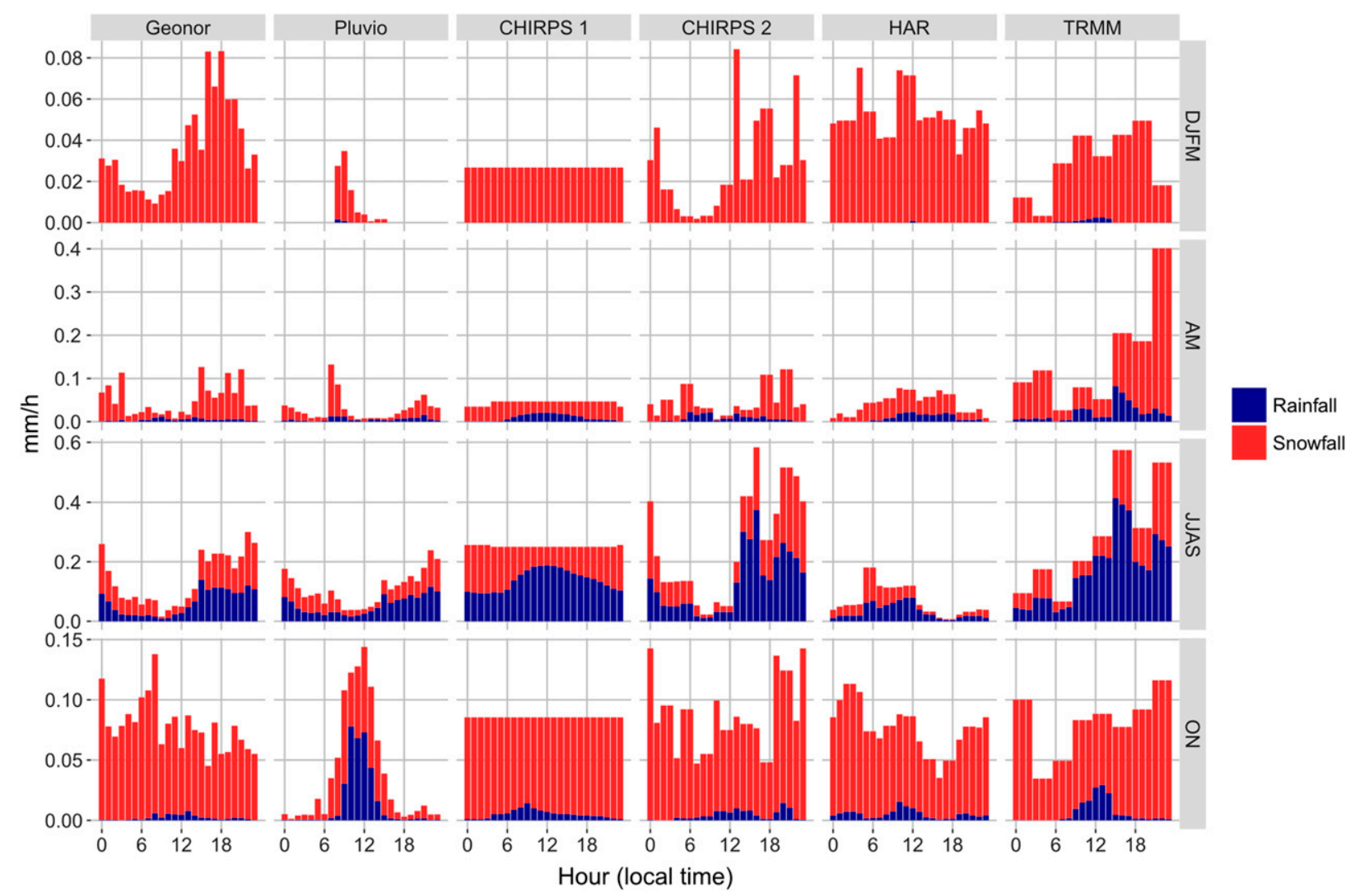

FIG. 5. Derived diurnal cycles of rainfall and snowfall for the year 2012-13 for the Pheriche catchment average for the winter (DJFM), premonsoon (AM), monsoon (JJAS), and postmonsoon (ON) seasons.

of the precipitation occurring during the monsoon season (against $60 \%$ with the Geonor dataset). Wagnon et al. (2013) and Salerno et al. (2015) both found a high monsoon precipitation share (respectively $80 \%$ and $90 \%$ ) at the Pyramid station using the EvK2-CNR precipitation measurements with classical tipping buckets and these studies both mentioned that the solid precipitation was underestimated by the tipping buckets. With the Geonor dataset the monsoon precipitation represents only $58 \%$ of the annual precipitation because the Geonor gauges measure more solid precipitation during the winter season (Fig. 4). The CHIRPS, HAR, and TRMM datasets also show differences in the seasonal repartition of precipitation. Figure 4 shows that seasonal variations in the HAR dataset are very different from the other datasets as the monsoon precipitation only represents $53 \%$ of the annual precipitation in the HAR dataset, whereas it is the main source of precipitation in the other datasets (from $60 \%$ up to $85 \%$ ). Moreover, most of the HAR precipitation occurs between the post and premonsoon seasons, when the temperatures are lower leading to a high proportion of snowfall $(76 \%)$.
The CHIRPS and TRMM data result in particularly high amounts of precipitation during the monsoon season $(76 \%$ and $77 \%)$ with a smaller proportion of snowfall.

\section{3) DIURNAL VARIATION OF PRECIPITATION}

Figure 5 represents the daily cycle of the precipitation for all datasets and for the different seasons. The two in situ precipitation datasets have very different patterns during winter, premonsoon and postmonsoon. The Geonor shows a broad maximum in the second half of the day with highest values around 1800 local time (LT). The Pluvio dataset shows peaks of precipitation around noon during postmonsoon and winter. This can be explained by the fact that the classical tipping buckets do not register the snow entering the bucket, when the temperature is below $0^{\circ} \mathrm{C}$. The snow accumulates inside the bucket and melts only later when the ambient temperature rises above $0^{\circ} \mathrm{C}$ during the day. Thus, the peak is mainly caused by the melting of the previously accumulated snow. This precipitation pattern results in different distributions of liquid and solid precipitation since air temperatures are applied to determine 


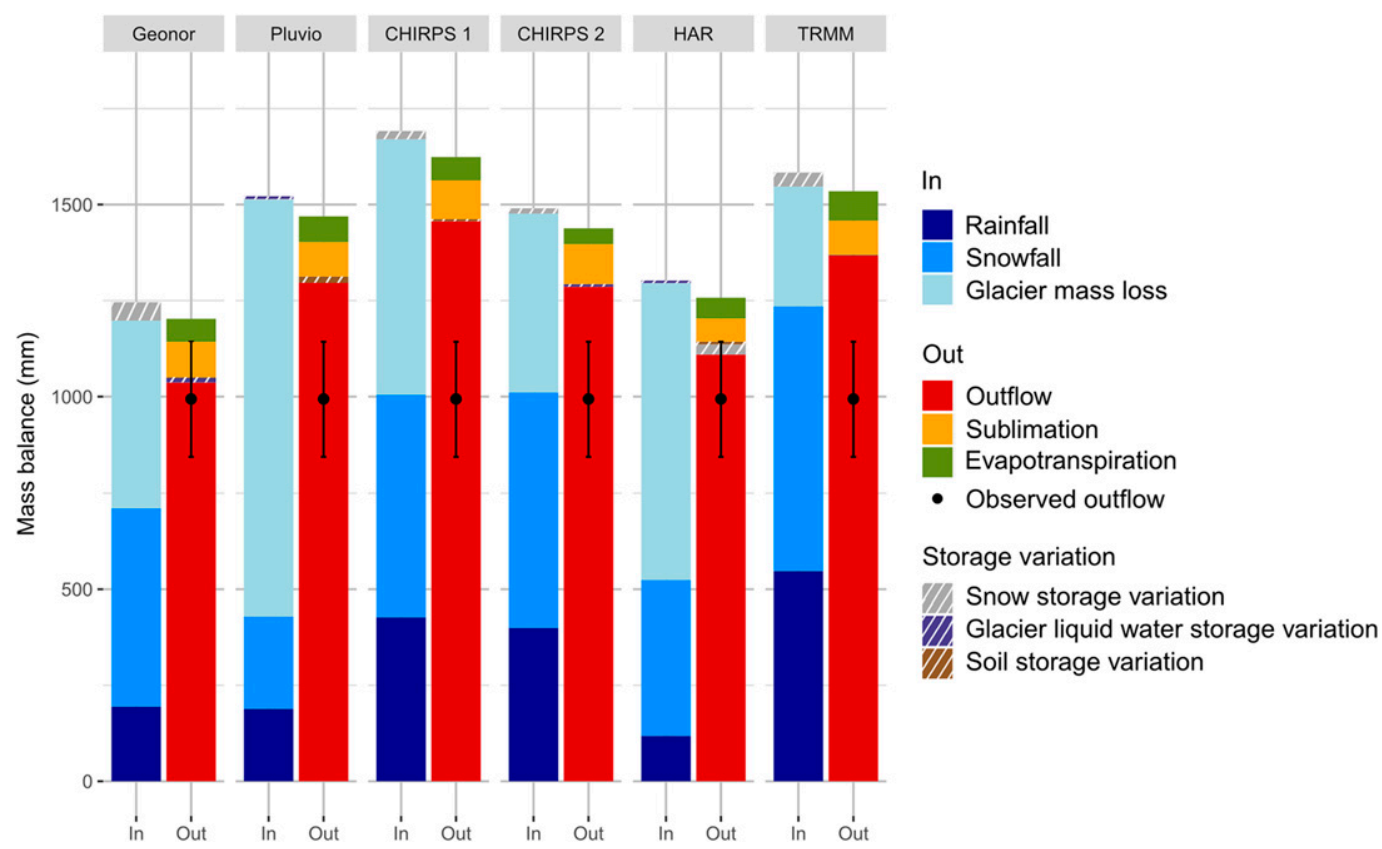

FIG. 6. Simulated water balance for the six precipitation datasets for the year 2012-13. For each dataset, the left column represents the water contributions for runoff (precipitation and ice melt), and the right column represents the water losses (outflow, evapotranspiration, and sublimation). The soil, englacial water, and snow storage variations are either considered as contributions or losses depending on their sign. Observed outflow at the Pheriche station is represented in black with an uncertainty of $15 \%$.

the precipitation phase. During premonsoon and postmonsoon, a significant part of the Pluvio precipitation is characterized as rainfall because the precipitation is recorded during daytime with temperatures above $0^{\circ} \mathrm{C}$. Thus, it is likely that a large fraction of the snowfall is wrongly attributed to liquid precipitation. In contrast, almost all precipitation obtained by the Geonor is defined as snowfall, since precipitation is mainly recorded during the evening and at night with temperatures below $0^{\circ} \mathrm{C}$. During the monsoon season, the Geonor and Pluvio datasets give similar precipitation patterns since the air temperatures at the Pheriche (4260m MSL) and Pyramid (5035 m MSL) stations are generally positive and the precipitation measured by both instruments is classified as rain.

The two CHIRPS datasets give different patterns of snowfall and rainfall distributions due to the different subdaily repartition of the precipitation. Particularly, during the monsoon season, the CHIRPS 1 dataset leads to a shift of the rainfall peak at noon compared to the evening peak obtained with the CHIRPS 2 dataset.

The TRMM dataset has a diurnal pattern similar to the Geonor dataset during the monsoon season with a peak of precipitation in the evening. TRMM clearly overestimates the precipitation during the premonsoon and monsoon seasons, particularly the evening snowfall events during premonsoon.

HAR shows diurnal winter and monsoon precipitation patterns different from the other datasets. In winter, HAR shows no particular diurnal variation and higher snowfall intensities than the other datasets. During monsoon season, precipitation intensities are lower, the peak of precipitation occurs in the morning and precipitation at night and during the evening remains limited.

\section{c. Impacts of the precipitation uncertainty on the simulated water balance components}

Figure 6 shows the annual simulated water balance for the year 2012-13 derived with each precipitation dataset. In all simulations, the sum of water losses is on average $46 \mathrm{~mm}$ below the sum of the annual contributions. This difference is essentially due to numerical errors (global model error of $0.81 \%$ ), but can also be partly ascribed to the model initialization, despite a 3-yr spinup.

The simulated annual outflow is clearly not directly proportional to the annual amount of precipitation. Datasets with high amounts of precipitation (CHIRPS and TRMM) lead to an overestimation of the annual outflow, but this is also the case for the Pluvio dataset 

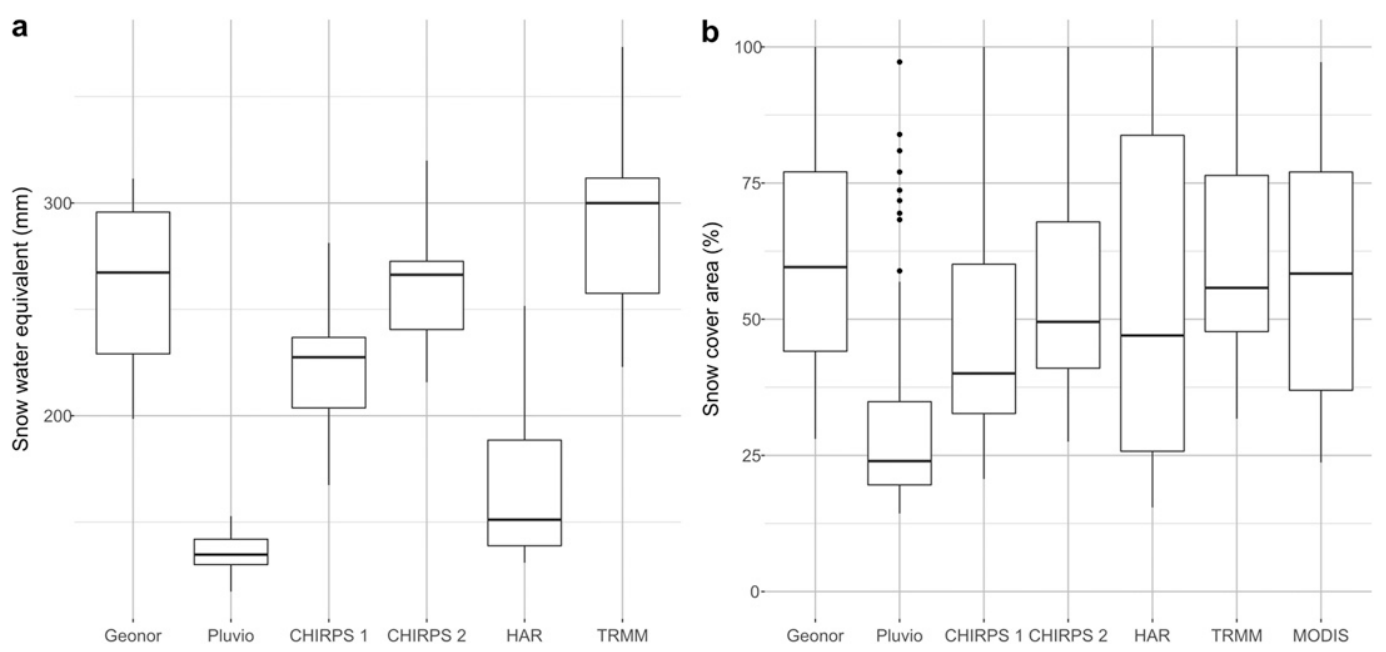

FIG. 7. Boxplot of the daily (a) SWE and (b) SCA for the year 2012-13 simulated with the six precipitation datasets. Observed SCA derived from daily MODIS satellite images is also shown.

with a low amount of precipitation. The annual amount of precipitation impacts the amount of ice melt. Large amounts of precipitation result in a low amount of glacier mass loss, whereas low amounts of precipitation result in large glacier mass losses. The snow and rainfall distribution and the temporal distribution of the precipitation also play major roles in the water balance: datasets with similar amounts of precipitation, but with different amounts of solid precipitation (i.e., the Pluvio and HAR datasets) result in different glacier mass losses and annual outflows. Similarly, the CHIRPS 2 dataset has the same annual amount of precipitation than CHIRPS 1 , but a different temporal distribution and leads to a lower glacier mass loss and annual outflow.

Concerning the losses by evapotranspiration and sublimation, all precipitation datasets lead to similar results with annual values around $150 \mathrm{~mm}$. Results also demonstrate that the simulated soil, snow, and englacial storages show small annual variations and that changes in the stored amounts are negligible for the annual water balance.

\section{1) SNOW COVER AREA AND SNOW WATER EQUIVALENT}

Figure 7 shows the simulated snow water equivalent (SWE) and snow cover area (SCA) during the glaciological year 2012-13 with respect to the used precipitation dataset. The daily SWE and SCA distributions for the catchment show a large variability, particularly for the SWE where distributions do not always overlap which each other.

The two in situ datasets, result in very different SWE and SCA. The Geonor dataset gives a median daily SWE of $235 \mathrm{~mm}$ and a median daily SCA of $60 \%$ of the catchment area, whereas the Pluvio dataset leads to very low daily SCA and SWE values. Most of the SCA values obtained with the Pluvio dataset range between $20 \%$ and $30 \%$ and the Pheriche basin is never fully covered by snow, which is not in agreement with the SCA derived from the MODIS images. The differences between the SCA and SWE values obtained with the Geonor and Pluvio datasets are clearly related to different amounts of annual snowfall (Table 3). The datasets CHIRPS 1 and 2 show the impact of the diurnal distribution of the precipitation on the snow cover simulation. CHIRPS 1 has less annual snowfall, which explains that CHIRPS 1 gives smaller daily SWE values than CHIRPS 2. Moreover, as the precipitation is uniformly distributed during the day, the maximum snowfall rates are smaller in the CHIRPS 1 dataset leading to a thinner snowpack and a quicker melting of the fresh snow (see Fig. 5). The CHIRPS 2 dataset with the hourly disaggregation using in situ data results in simulated SCA closer to MODIS. The HAR dataset has a low SWE distribution, but a large SCA variability with a mean SCA of $47 \%$. Most of the HAR precipitation occurs during winter and is classified as solid precipitation, which explains the high SCA. Nevertheless, the snow melts quickly, when the temperature increases and the little snowfall during the monsoon season causes the low SWE values and the low minimum SCA. The large amount of snowfall in the TRMM dataset leads to a median snow coverage of $55 \%$ in the catchment. The SWE value is also higher than obtained with the other datasets due to a larger snow accumulation. The comparison between the six precipitation datasets shows that the simulated SWE and SCA are not linearly correlated to the 


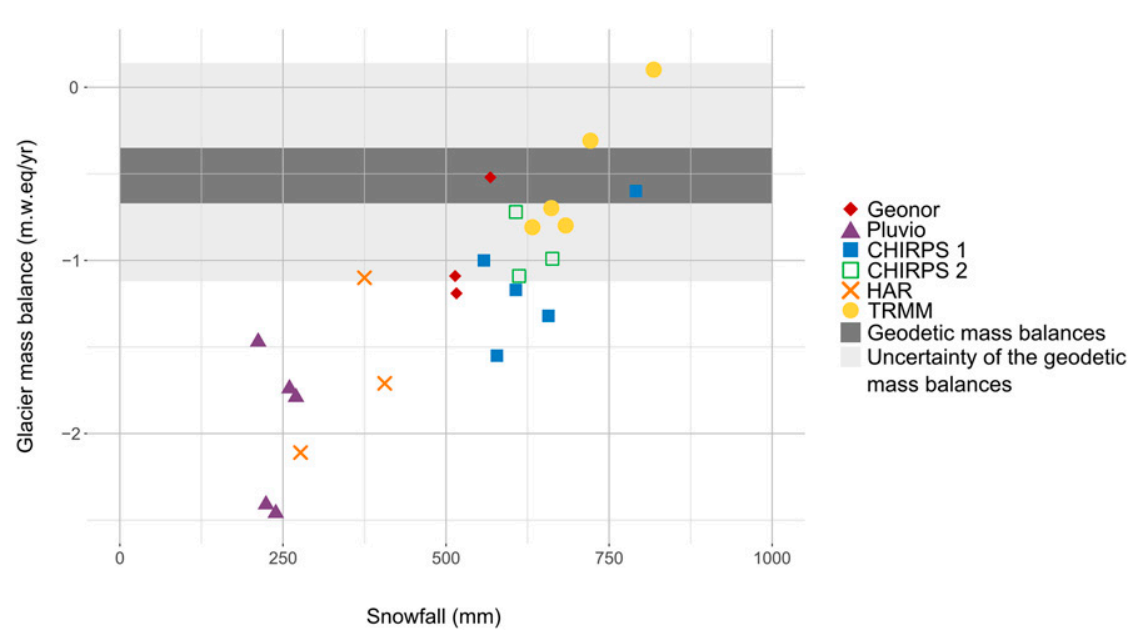

FIG. 8. Correlation between the simulated annual glacier mass balance and annual snowfall amounts for the six precipitation datasets and the three glaciological years 2012-15. The dark gray rectangle represents the range of the geodetic mass balances from the literature, and the light gray rectangle represent the range of uncertainty of the geodetic mass balances (cf. Table 5).

annual amount of snowfall. For example, the Geonor dataset leads to a higher median SWE value compared to the CHIRPS 1 dataset despite the lower amount of snowfall $(516 \mathrm{~mm}$ for the Geonor dataset versus $578 \mathrm{~mm}$ for CHIRPS 1 for the year 2012-13). Similarly, the Pluvio and HAR both result in low median SWE values (lower than $150 \mathrm{~mm}$ ) with different amounts of annual snowfall $(240 \mathrm{~mm}$ for the Pluvio dataset versus $406 \mathrm{~mm}$ for HAR). This shows that the seasonal and hourly distribution of the solid precipitation has a large impact on the simulated snow cover.

\section{2) GLACIER COMPONENT}

Figure 8 illustrates the impact of the precipitation dataset on the simulated glacier mass balance. The simulated glacier mass balance is well correlated to the annual amount of snowfall $\left(R^{2}=0.7\right)$. Nevertheless, the CHIRPS 1 and CHIRPS 2 datasets show that similar snowfall amounts can lead to different simulated glacier mass balances. For instance, for the glaciological year 2012-13, while the annual amounts of snowfall of the CHIRPS 1 and CHIRPS 2 datasets correspond to 578 and $612 \mathrm{~mm}$, the derived glacier mass balances are equal to -1.55 and $-1.09 \mathrm{~m}$ water equivalent (w.e.) $\mathrm{yr}^{-1}$, that is, an increase of $6 \%$ of the snowfall amount leads to a decrease of $30 \%$ of the glacier mass balance.

The large differences between the mass balances simulated with the CHIRPS 1 and CHIRPS 2 datasets shows the impact of the diurnal cycle of the precipitation on the glacier mass balance: the CHIRPS 2 dataset leads to more precipitation during the afternoon and night in the monsoon season (see Fig. 5), resulting in larger snow accumulation (Fig. 7) and less melting (Fig. 6). Figure 8 and Table 5 also show the range of values of glacier mass balances determined with geodetic methods (Bolch et al. 2012; Gardelle et al. 2013; Nuimura et al. 2015; King et al. 2017; Brun et al. 2017). Only the order of magnitude of these mass balances can be compared to the simulated annual mass balances since the considered areas and the time periods are not the same in all studies. The Pluvio and HAR datasets result in very negative glacier mass balances (with a mean annual mass balances respectively equal to -1.98 and $-1.52 \mathrm{~m}$ w.e. $\mathrm{yr}^{-1}$ ) due to the lack of snow accumulation on the glaciers and the excess of ice melt and differ strongly from observed glacier mass balances. The mass balances simulated

TABLE 5. Geodetic mass balances estimated on the Khumbu-Changri glacier and the Pheriche catchment.

\begin{tabular}{clll}
\hline \hline $\begin{array}{c}\text { Glacier mass balances } \\
\left(\mathrm{m} \text { w.e. } \mathrm{yr}^{-1}\right)\end{array}$ & \multicolumn{1}{c}{ Period } & \multicolumn{1}{c}{ Area } & \multicolumn{1}{c}{ Reference } \\
\hline$-0.32 \pm 0.09$ & $2000-16$ & Pheriche catchment & Brun et al. (2017) \\
$-0.38 \pm 0.52$ & $2002-07$ & Khumbu-Changri glacier & Bolch et al. (2012) \\
$-0.67 \pm 0.45$ & $2000-08$ & Khumbu-Changri glacier & Nuimura et al. (2015) \\
$-0.47 \pm 0.18$ & $1999-2011$ & Khumbu-Changri glacier & Gardelle et al. (2013) \\
$-0.35 \pm 0.15$ & $2000-16$ & Khumbu-Changri glacier & King et al. (2017) \\
\hline
\end{tabular}




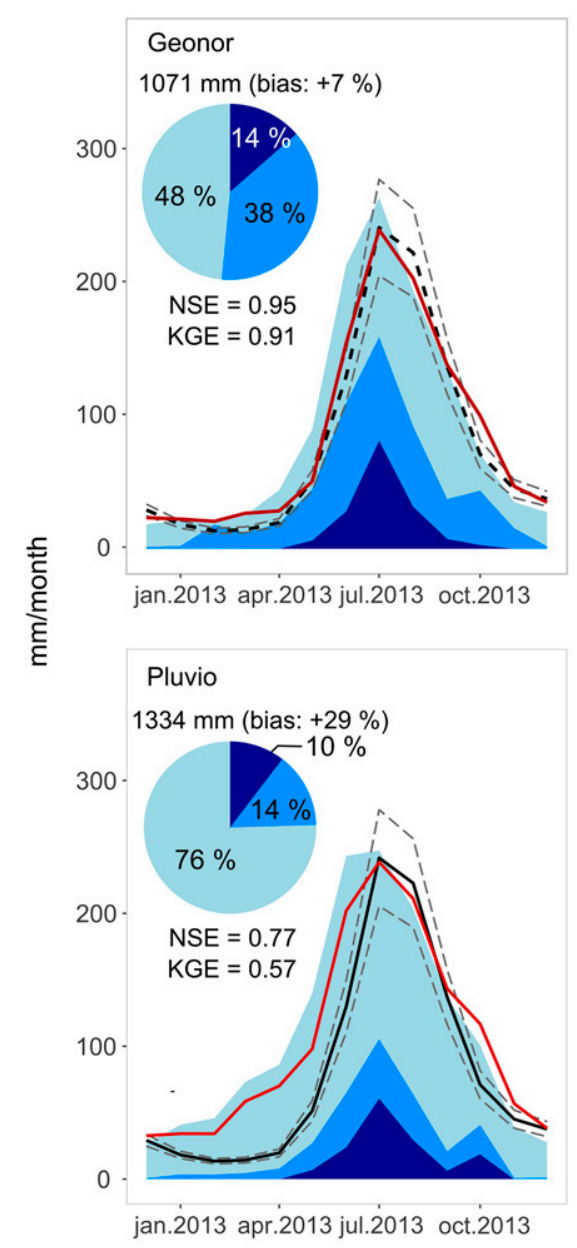

Net rainfall
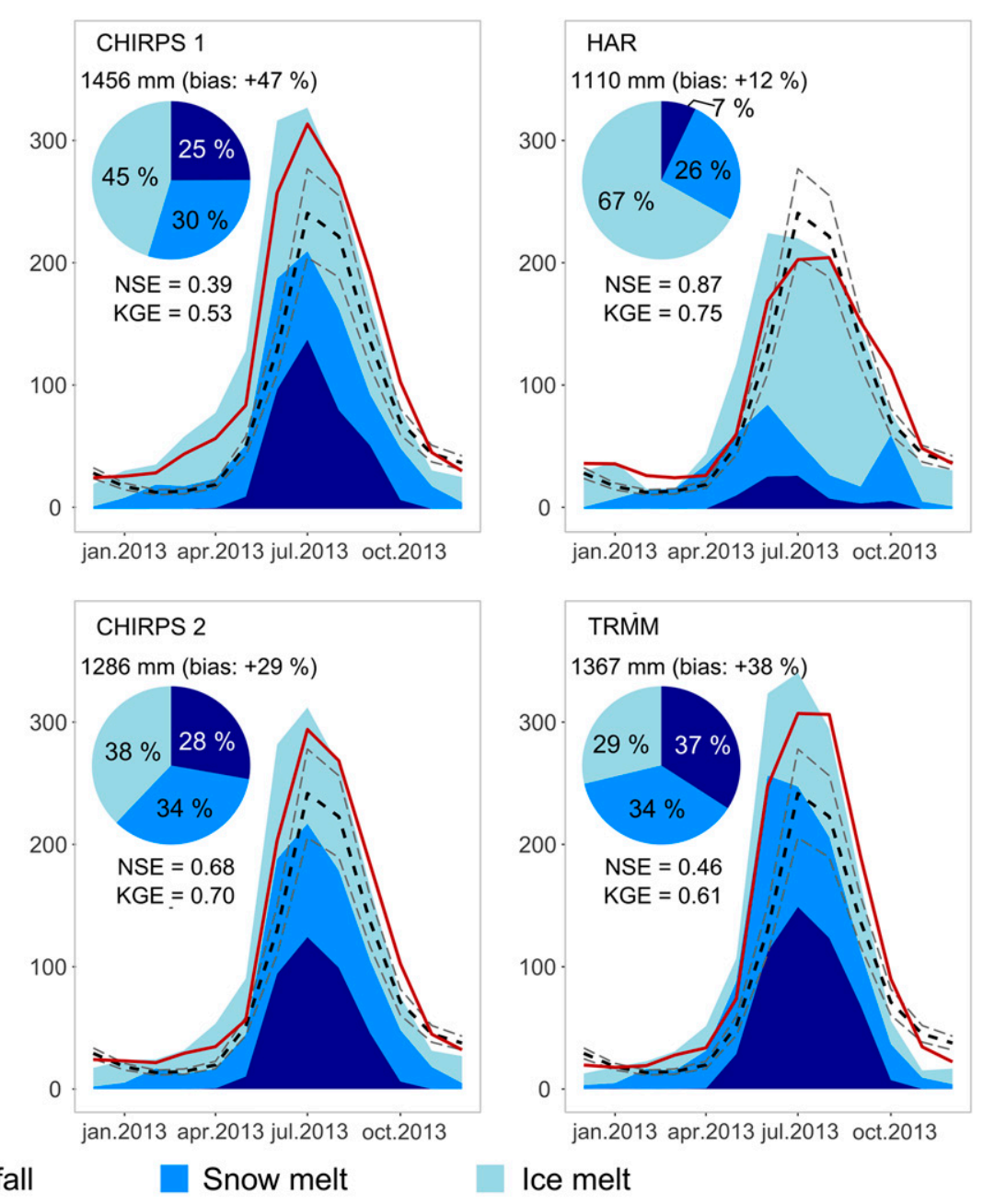

- Simulated outflow

-. - Observed outflow

FIG. 9. Simulated annual and monthly outflow and flow components with the six precipitation datasets for the glaciological year 2012-13. Observed outflows (black dashed line) are represented with a $15 \%$ interval of uncertainty.

with the Geonor dataset (ranging between -0.5 and $-1.19 \mathrm{~m}$ w.e. $\mathrm{yr}^{-1}$ ) are close to the geodetic mass balances and remain within the interval of uncertainty. Concerning the CHIRPS datasets, the mass balances obtained with the CHIRPS 1 dataset are lower than the mass balances simulated with the Geonor dataset, whereas the CHIRPS 1 snowfall amounts are higher. The hourly distributed precipitation of the CHIRPS 2 dataset leads to simulated mass balances closer to the geodetic mass balances values. The glacier mass balances simulated with the TRMM dataset are all within the range of uncertainty of the geodetic mass balances. However, for the glaciological year 2010-11, the TRMM leads to a positive mass balance which does not seem realistic. The large amounts of snow accumulation produced by the TRMM dataset cause low amounts of ice melt, which explains the higher mass balances obtained with the TRMM dataset.

\section{3) RUNOFF COMPONENTS}

Figure 9 illustrates the simulated annual and monthly discharges and flow components for the glaciological year 2012-13 derived for the six precipitation datasets. Here, the sum of the three flow components (ice melt, snowmelt, and net rainfall) corresponds to the total production of runoff. At a monthly time step, the production of runoff is not necessarily equal to the river outflow because the time of transfer within the catchment is not taken into account.

\section{(i) Annual contributions}

Like applied precipitation datasets, the simulated annual outflow shows a considerable variability: it ranges 
from $1071 \mathrm{~mm}$ for the Geonor dataset to $1456 \mathrm{~mm}$ for the CHIRPS 1 dataset. Nevertheless, while the maximum and minimum annual precipitation amounts vary by a factor of 2.9 (1235 $\mathrm{mm}$ for the TRMM dataset and $429 \mathrm{~mm}$ for the Pluvio dataset for the year 2012-13), the ratio between the maximum and minimum annual outflow is only on the order of 1.3. Figures 6 and 9 show that in cases with low annual precipitation amounts (and specifically with low annual snowfall amounts), additional ice melt leads to a compensation in the simulated annual outflows. As a result, the uncertainty related to the precipitation has a strong impact the estimation of the hydrological contributions to the outflow. With the different precipitation datasets, the ice melt contribution ranges from $29 \%$ to $76 \%$, the snowmelt from $14 \%$ to $34 \%$ and the net rainfall from $7 \%$ to $37 \%$. The HAR and Pluvio datasets, which present low annual precipitation amounts, result in higher simulated annual outflow compared to the Geonor dataset due to larger amounts of ice melt. In contrast, the CHIRPS and TRMM datasets overestimate the precipitation and produce too much runoff compared to the observed outflow (bias between $+29 \%$ and $+47 \%$ ). The Geonor and HAR both give annual outflows similar to the observed outflow but with different contributions for the outflow components $(67 \%$ of ice melt for HAR and $48 \%$ for Geonor).

\section{(ii) Monthly contributions}

For all the datasets, the production of runoff is higher than the river outflow before the month of July, and lower in the period from August until December. This is due to the variation of the groundwater and englacial storage in the model: liquid water is stored in the soil or glacier reservoirs during the premonsoon and monsoon and then released during postmonsoon and winter (Mimeau et al. 2018).

The Geonor dataset results in the best simulated outflow (NSE and KGE equal to 0.95 and 0.91 for daily discharges) except in October 2013 when the simulated discharge is overestimated. This month is marked by the passage of the Phailin typhoon on October 13, which is not accurately reproduced by the model due to a too quick hydrological response to the event. The Geonor dataset results in mixed contributions of net rainfall, snowmelt, and ice melt during the monsoon season, a main contribution from snowmelt during the premonsoon, and a main contribution of ice melt during postmonsoon and winter.

The simulation with the Pluvio dataset leads to an overestimation of the winter and premonsoon discharges with a large contribution of ice melt. This is due to the low amount of snowfall during winter: the snow cover melts rapidly and the glaciers are exposed and contribute significantly already in March to the outflow.

With the HAR dataset, the discharges are well simulated (0.87 NSE and 0.75 KGE) particularly during low flow periods. The simulations with HAR generate a large amount of ice melt compared to the Geonor dataset and the seasonal repartition of the flow components is very different between the two datasets. HAR results in a large amount of snowfall during winter, which delays the beginning of the ice melt and the rise of the discharges to May and is, thus, consistent with the observed outflow. However, HAR overestimates the ice melt production during the monsoon season, due to a lack of precipitation to produce snow accumulation at high altitude to limit the glacier melt (Fig. 7).

Concerning the CHIRPS datasets, the discharges are well simulated outside the monsoon season, but the excess of precipitation during the monsoon season leads to overestimated discharges. The simulations with the CHIRPS 1 and the CHIRPS 2 datasets show the impact of the diurnal cycle of the precipitation on the simulated annual and seasonal outflow. Similar amounts of precipitation with different subdaily distributions give different solid and liquid precipitation repartition and, thus, different amounts of annual outflow: the uniformly distributed dataset (CHIRPS 1) simulates more outflow than the hourly distributed dataset (CHIRPS 2). The uniform distribution of the precipitation particularly impacts the winter and premonsoon discharges due to an excess of ice melt.

The TRMM and CHIRPS 2 datasets give almost the same amount of annual outflow, but different seasonal discharges and contributions to the outflow. Figure 4 shows that TRMM overestimates precipitation during the monsoon season as well as snowfalls during premonsoon. Figure 9 demonstrates that the outflow in this case is mainly controlled by snowmelt during premonsoon, while the melting of ice only begins in June. In postmonsoon and winter the contribution of snow and ice melt remains small.

\section{(iii) Subdaily variations of the flow components}

Figure 10 shows the diurnal variations of the production of ice melt, snowmelt, net rainfall and total outflow for each precipitation dataset. Except for monsoon net rainfall, the total runoff is produced by snowmelt and ice melt during day time. For all datasets, the diurnal variations of the outflow is not accurately simulated with a systematic overestimation of the midday peak. Particularly during the monsoon season, the model fails to simulate the observed diurnal peak occurring in the evening (between 2100 


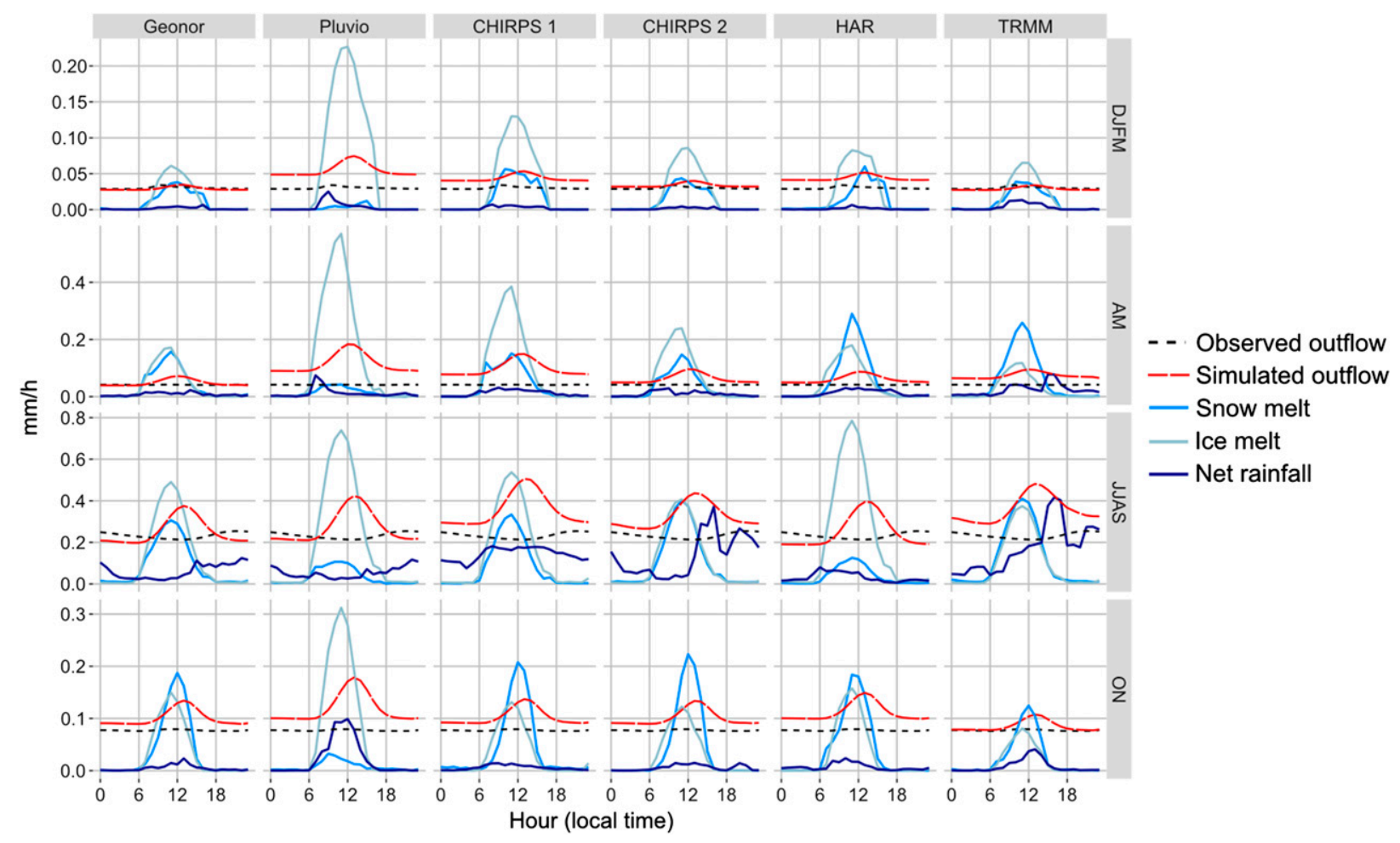

FIG. 10. Derived diurnal cycles of the observed and simulated discharges and the flow components for the year 2012-13 for the Pheriche catchment average for the winter (DJFM), premonsoon (AM), monsoon (JJAS), and postmonsoon (ON) seasons.

and $0000 \mathrm{LT}$ ). This evening peak is related to the diurnal cycle of the monsoon precipitation with a maximum in the late afternoon/evening as well as by the lag time due to the transfer through the catchment to the outlet after the melting occurring in the middle of the day. Reasons for the mismatch between simulated and observed diurnal outflow are discussed in Mimeau et al. (2018).

The comparison between the subdaily variations of the outflow and flow components simulated with the six precipitation datasets show that a poor representation of the diurnal precipitation cycle amplifies the error on the simulated outflow. For instance, outside the monsoon season, the runoff production simulated with the Pluvio dataset is completely different from the results obtained with the other datasets. The wrongly attributed peak of rainfall at noon on the Pluvio dataset leads to a maximum in the rainfall contribution, which is not simulated with the other datasets. The lack of measured solid precipitation also leads to large amounts of ice melt in the middle of the day when the temperature is maximal. The excess of ice melt then leads to higher peaks of simulated discharge. The same phenomenon is observed with the two CHIRPS datasets: the uniform distribution of the daily precipitation in CHIRPS 1 impacts the diurnal production of runoff with smaller amounts of snowmelt and higher amounts of ice melt.

\section{d. Impact of the altitudinal gradients on the modeled water balance components}

Table 6 presents the simulated glaciers mass balances and annual outflow simulated with the different sets of lapse rates. The temperature and precipitation lapse rates directly impact the snow accumulation on glaciers. In a catchment with $4000 \mathrm{~m}$ of altitude difference, even low values of precipitation gradients can lead to significant differences in the precipitation at high altitude. The hourly lapse rates lead to higher glacier accumulations than the other gradients because they are mainly positive in winter and produce more snowfall at high altitude.

The lapse rates indirectly impact the glacier mass balances and the ice melt production. The simulated mass balances range from $-1.03 \mathrm{~m}$ w.e. $\mathrm{yr}^{-1}$ with the hourly lapse rates to $-1.46 \mathrm{~m}$ w.e. $\mathrm{yr}^{-1}$ with the annual gradient. The mean annual outflows simulated with the daily, monthly, and annual lapse rates are higher than the annual outflow simulated with the hourly lapse rates due to the larger amounts of ice melt.

This shows that the applied spatial distribution also has an impact on the hydrological modeling and the 
TABLE 6. Mean annual glacier mass balances, outflows, and flow components simulated with different temperature and precipitation lapse rates for the period 2012-15. Definitions are as follows: LR is lapse rate, H is hourly, D is daily, M is monthly, A is annual, B is benchmark, $P$ is precipitation, MB is mass balance, Acc is accumulation, Abl is ablation, $Q$ is outflow, $\mathrm{RF}$ is net rainfall, $\mathrm{SM}$ is snowmelt, and IM is ice melt.

\begin{tabular}{|c|c|c|c|c|c|c|c|c|c|c|}
\hline \multirow[b]{2}{*}{ LR } & \multirow[b]{2}{*}{$P(\mathrm{~mm})$} & \multicolumn{3}{|c|}{ Glacier mass balance } & \multicolumn{3}{|c|}{ Discharges } & \multicolumn{3}{|c|}{ Flow components } \\
\hline & & $\mathrm{MB}(\mathrm{m})$ & Acc. $(\mathrm{m})$ & Abl. (m) & $Q(\mathrm{~mm})$ & Bias (\%) & $\mathrm{KGE}$ & $\mathrm{RF}(\mathrm{mm})$ & $\mathrm{SM}(\mathrm{mm})$ & $\mathrm{IM}(\mathrm{mm})$ \\
\hline $\mathrm{H}$ & 645 & -1.03 & 0.573 & -1.603 & 921 & $-3 \%$ & 0.88 & $113(12 \%)$ & $348(38 \%)$ & $460(50 \%)$ \\
\hline $\mathrm{D}$ & 600 & -1.35 & 0.514 & -1.864 & 1018 & $7 \%$ & 0.81 & $106(10 \%)$ & $335(33 \%)$ & $577(57 \%)$ \\
\hline M & 575 & -1.43 & 0.477 & -1.907 & 1027 & $8 \%$ & 0.8 & $99(10 \%)$ & $333(32 \%)$ & $595(58 \%)$ \\
\hline A & 588 & -1.46 & 0.487 & -1.947 & 1054 & $11 \%$ & 0.77 & $107(10 \%)$ & $332(32 \%)$ & $615(58 \%)$ \\
\hline $\mathrm{B}$ & 597 & -1.1 & 0.516 & -1.616 & 907 & $-4 \%$ & 0.81 & $91(10 \%)$ & $347(38 \%)$ & $468(52 \%)$ \\
\hline
\end{tabular}

estimation of the flow components. The uncertainty related to the lapse rates is lower than the uncertainty related to the precipitation dataset since the ice melt contribution ranges from $50 \%$ to $58 \%$ for the different temperature and precipitation lapse rates. For a small high-elevated catchment, the results show that hourly lapse rates are more suitable since the annual lapse rate leads to an underestimation of the winter precipitation.

\section{Conclusions and perspectives}

In this study we compare the spatial distribution and temporal variability of several precipitation datasets for a small high-elevated catchment and evaluated the impact of the precipitation uncertainty on the glaciohydrological modeling.

The precipitation datasets show a large variability particularly in terms of annual amount, seasonal and subdaily variability. First, the comparison between two in situ precipitation datasets measured with different types of rain gauges showed that classical tipping buckets are not able to produce reliable precipitation data during postmonsoon and winter seasons. The classical tipping buckets strongly underestimate the solid precipitation and do not represent correctly the diurnal distribution of the precipitation. Geonor rain gauges seem to measure more realistic winter precipitation. However, the spatial interpolation of the in situ measurements leads to additional uncertainties: the mean annual catchment precipitation ranges from 575 to $645 \mathrm{~mm} \mathrm{yr}^{-1}$ when using different sets of temperature and precipitation altitudinal gradients. Other precipitation datasets used in this study (TRMM, CHIRPS, and HAR) showed a large variability in annual amounts, as well as seasonal and subdaily distributions. The mean annual precipitation estimated on the Pheriche catchment with these gridded precipitation datasets ranges from 410 to $1190 \mathrm{~mm} \mathrm{yr}^{-1}$, and the fraction of annual precipitation occurring during the monsoon season ranges from $53 \%$ with the HAR dataset to $84 \%$ with the
Pluvio dataset. These datasets show different spatial distribution of the annual precipitation with a southnorth gradient for the CHIRPS dataset and a west-east gradient for the HAR dataset. The comparison between the precipitation datasets also showed that the subdaily distribution of the precipitation has a significant impact on the rainfall and snowfall distribution.

The simulations using the glacio-hydrological model DHSVM-GDM demonstrate that the choice of a given precipitation dataset has a very strong impact on the simulated annual outflow as well as the flow components. The annual outflow simulated with the different datasets range from 1035 to $1456 \mathrm{~mm}$ for the glaciological year 2012-13 and the ice melt contribution to the outflow range from $28 \%$ to $76 \%$. The datasets, which underestimate the annual precipitation (HAR and classical tipping buckets), give higher estimations of the ice melt component. Different precipitation datasets can lead to well simulated discharges, but also to very different estimations of the ice and snowmelt contributions to the outflow (e.g., Geonor and HAR). On the opposite, similar precipitation datasets can lead to very different simulated discharges and contributions to the outflow (e.g., CHIRPS 1 and CHIRPS 2). This means that in a high-altitude region with high precipitation uncertainties the use of a given dataset can lead to large errors on the estimation of the ice and snowmelt contributions to the outflow, even if the discharge is correctly simulated.

The diurnal cycle of the precipitation greatly impacts the simulated snow cover and glacier accumulation and, thus, indirectly influence the simulation of ice and snowmelt. This highlights the importance of considering hourly time steps to accurately simulate the glacio-hydrological processes. As a result it is important to evaluate the performance of the precipitation datasets at a subdaily time scale.

The choice of the temperature and precipitation gradients to interpolate in situ precipitation measurements leads to an uncertainty of $15 \%$ on the simulated annual outflow and an uncertainty around $8 \%$ on the ice melt 
components. This study shows that, for a small high elevated catchment, the Geonor precipitation data interpolated with an hourly precipitation gradient leads to best results in terms of annual and seasonal outflow as well as a good representation of the snow cover area and glacier mass balance.

The spatial resolution of the TRMM and HAR datasets is not adapted for small catchments since it is too coarse for the study area and the precipitation may not be representative for the basin. It would be interesting to reproduce this study over a larger catchment (Dudh Koshi basin) in order to evaluate the uncertainty related to the precipitation dataset at a larger scale. Moreover, instead of using a gridded precipitation datasets, the glacio-hydrological model could be forces by the output of a high-resolution climate model. High-resolution climate models enable simulating precipitation fluxes at small spatial resolution and have a better representation of the spatial distribution of the precipitation at local scale (Ménégoz et al. 2013). Collier and Immerzeel (2015) and Karki et al. (2017) both used the Weather Research and Forecasting (WRF) Model at a 1-km resolution to simulate the atmospheric circulation on Himalayan catchments. They found that running the WRF Model at high resolution with an explicit simulation of the convection improves the simulation of precipitation, in particular at high elevation. It also enables a better representation of the spatial pattern, magnitude, and the seasonal and diurnal cycle of the precipitation. Moreover, Li et al. (2017) used precipitation data generated at $300-\mathrm{m}$ spatial resolution with WRF for hydrological simulations of an $800-\mathrm{km}^{2}$ basin in the Himalayas. These studies show encouraging results and using WRF simulations at a kilometer or subkilometer scale shows good potential to generate forcing data for glacio-hydrological models in a small and high-elevated catchment such as the Pheriche catchment and, thus, reduces the uncertainty of the precipitation forcing data.

Acknowledgments. This work has been supported by the French National Research Agency (ANR) through the ANR-13-SENV-0005-04/05-PRESHINE project and by a grant from Labex OSUG@2020 (investissement d'avenir, ANR 10 LABX56). It has benefited from data from the French Service d'Observation GLACIOCLIM (https://glacioclim.osug.fr/) and from Ev-K2-CNR (www.evk2cnr.org). The DHSVMGDM model was made available by Chris Frans (Department of Civil and Environmental Engineering, University of Washington). The works of Yves Lejeune (CNRM-GAME) for correcting precipitation data in the GLACIOCLIM database.

\section{REFERENCES}

Andermann, C., S. Bonnet, and R. Gloaguen, 2011: Evaluation of precipitation data sets along the Himalayan front. Geochem. Geophys. Geosyst., 12, Q07023, https://doi.org/10.1029/ $2011 \mathrm{GC} 003513$

Barry, R. G., and R. J. Chorley, 2009: Atmosphere, Weather and Climate. Routledge, 536 pp.

Bolch, T., and Coauthors, 2012: The state and fate of Himalayan glaciers. Science, 336, 310-314, https://doi.org/10.1126/science.1215828.

Bookhagen, B., and D. W. Burbank, 2006: Topography, relief, and TRMM-derived rainfall variations along the Himalaya. Geophys. Res. Lett., 33, L08405, https://doi.org/10.1029/ 2006GL026037.

_ and — 2010: Toward a complete Himalayan hydrological budget: Spatiotemporal distribution of snowmelt and rainfall and their impact on river discharge. J. Geophys. Res., 115, F03019, https://doi.org/10.1029/2009JF001426.

Brun, F., E. Berthier, P. Wagnon, A. Kääb, and D. Treichler, 2017: A spatially resolved estimate of High Mountain Asia glacier mass balances from 2000 to 2016. Nat. Geosci., 10, 688-673, https://doi.org/10.1038/ngeo2999.

Cannon, F., L. M. Carvalho, C. Jones, A. Hoell, J. Norris, G. N. Kiladis, and A. A. Tahir, 2017: The influence of tropical forcing on extreme winter precipitation in the western Himalaya. Climate Dyn., 48, 1213-1232, https://doi.org/10.1007/s00382-016-3137-0.

Ceglar, A., A. Toreti, G. Balsamo, and S. Kobayashi, 2017: Precipitation over monsoon Asia: A comparison of reanalyses and observations. J. Climate, 30, 465-476, https://doi.org/10.1175/ JCLI-D-16-0227.1.

Chevallier, P., and Coauthors, 2017: Paprika-Preshine hydrology data sets in the Everest Region (Nepal) 2010-18. Database, https://doi.org/10.23708/000521.

Collier, E., and W. W. Immerzeel, 2015: High-resolution modeling of atmospheric dynamics in the Nepalese Himalaya. J. Geophys. Res. Atmos., 120, 9882-9896, https://doi.org/ 10.1002/2015JD023266.

Dee, D. P., and Coauthors, 2011: The ERA-Interim reanalysis: Configuration and performance of the data assimilation system. Quart. J. Roy. Meteor. Soc., 137, 553-597, https://doi.org/10.1002/qj.828.

Eeckman, J., P. Chevallier, A. Boone, L. Neppel, A. De Rouw, F. Delclaux, and D. Koirala, 2017: Providing a non-deterministic representation of spatial variability of precipitation in the Everest region. Hydrol. Earth Syst. Sci., 21, 4879, https://doi.org/10.5194/ hess-21-4879-2017.

Førland, E., and Coauthors, 1996: Manual for operational correction of Nordic precipitation data. DNMI Rep. 24/96, 66 pp.

Froidurot, S., I. Zin, B. Hingray, and A. Gautheron, 2014: Sensitivity of precipitation phase over the Swiss Alps to different meteorological variables. J. Hydrometeor., 15, 685-696, https://doi.org/10.1175/JHM-D-13-073.1.

Funk, C., and Coauthors, 2015: The climate hazards infrared precipitation with stations-A new environmental record for monitoring extremes. Sci. Data, 2, 150066, https://doi.org/ 10.1038/sdata.2015.66.

Gardelle, J., E. Berthier, Y. Arnaud, and A. Kaab, 2013: Corrigendum to "Region-wide glacier mass balances over the Pamir-Karakoram-Himalaya during 1999-2011" published in The Cryosphere, 7, 1263-1286, 2013. Cryosphere, 7, 18851886, https://doi.org/10.5194/tc-7-1885-2013.

Gupta, H. V., H. Kling, K. K. Yilmaz, and G. F. Martinez, 2009: Decomposition of the mean squared error and NSE performance criteria: Implications for improving hydrological 
modelling. J. Hydrol., 377, 80-91, https://doi.org/10.1016/ j.jhydrol.2009.08.003.

Huffman, G. J., and Coauthors, 2007: The TRMM multisatellite precipitation analysis (TMPA): Quasi-global, multiyear, combinedsensor precipitation estimates at fine scales. J. Hydrometeor., 8 , 38-55, https://doi.org/10.1175/JHM560.1.

Hughes, M., J. D. Lundquist, and B. Henn, 2017: Dynamical downscaling improves upon gridded precipitation products in the Sierra Nevada, California. Climate Dyn., https://doi.org/ 10.1007/s00382-017-3631-z

Immerzeel, W. W., L. P. Van Beek, and M. F. Bierkens, 2010: Climate change will affect the Asian water towers. Science, 328, 1382-1385, https://doi.org/10.1126/science.1183188.

_- F. Pellicciotti, and A. B. Shrestha, 2012: Glaciers as a proxy to quantify the spatial distribution of precipitation in the Hunza basin. Mt. Res. Dev., 32, 30-38, https://doi.org/10.1659/MRDJOURNAL-D-11-00097.1.

Immerzeel, W., L. Petersen, S. Ragettli, and F. Pellicciotti, 2014: The importance of observed gradients of air temperature and precipitation for modeling runoff from a glacierized watershed in the Nepalese Himalayas. Water Resour. Res., 50, 2212-2226, https://doi.org/10.1002/2013WR014506.

Jarosch, A. H., F. S. Anslow, and G. K. Clarke, 2012: High-resolution precipitation and temperature downscaling for glacier models. Climate Dyn., 38, 391-409, https://doi.org/10.1007/ s00382-010-0949-1.

Jennings, K. S., T. S. Winchell, B. Livneh, and N. P. Molotch, 2018: Spatial variation of the rain-snow temperature threshold across the Northern Hemisphere. Nat. Commun., 9, 1148, https://doi.org/10.1038/s41467-018-03629-7.

Kääb, A., D. Treichler, C. Nuth, and E. Berthier, 2015: Brief communication: Contending estimates of 2003-2008 glacier mass balance over the Pamir-Karakoram-Himalaya. Cryosphere, 9, 557-564, https://doi.org/10.5194/tc-9-557-2015.

Kalnay, E., and Coauthors, 1996: The NCEP/NCAR 40-Year Reanalysis Project. Bull. Amer. Meteor. Soc., 77, 437-471, https:// doi.org/10.1175/1520-0477(1996)077<0437:TNYRP > 2.0.CO;2.

Karki, R., S. ul Hasson, L. Gerlitz, U. Schickhoff, T. Scholten, and J. Böhner, 2017: Quantifying the added value of convectionpermitting climate simulations in complex terrain: A systematic evaluation of WRF over the Himalayas. Earth Syst. Dyn., 8, 507, https://doi.org/10.5194/esd-8-507-2017.

Kaser, G., M. Großhauser, and B. Marzeion, 2010: Contribution potential of glaciers to water availability in different climate regimes. Proc. Natl. Acad. Sci. USA, 107, $20223-$ 20 227, https://doi.org/10.1073/pnas.1008162107.

Kattel, D., T. Yao, K. Yang, L. Tian, G. Yang, and D. Joswiak, 2013: Temperature lapse rate in complex mountain terrain on the southern slope of the central Himalayas. Theor. Appl. Climatol., 113, 671-682, https://doi.org/10.1007/s00704-012-0816-6.

King, O., D. J. Quincey, J. L. Carrivick, and A. V. Rowan, 2017: Spatial variability in mass change of glaciers in the Everest region, central Himalaya, between 2000 and 2015. Cryosphere, 11, 407-426, https://doi.org/10.5194/tc-11-407-2017.

Lang, T. J., and A. P. Barros, 2004: Winter storms in the central Himalayas. J. Meteor. Soc. Jpn. Ser. II, 82, 829-844, https:// doi.org/10.2151/jmsj.2004.829.

L'hôte, Y., P. Chevallier, A. Coudrain, Y. Lejeune, and P. Etchevers, 2005: Relationship between precipitation phase and air temperature: Comparison between the Bolivian Andes and the Swiss Alps. Hydrol. Sci. J., 50, 997, https://doi.org/ 10.1623/hysj.2005.50.6.989.
Li, L., D. J. Gochis, S. Sobolowski, and M. D. Mesquita, 2017: Evaluating the present annual water budget of a Himalayan headwater river basin using a high-resolution atmospherehydrology model. J. Geophys. Res. Atmos., 122, 4786-4807, https://doi.org/10.1002/2016JD026279.

Maussion, F., D. Scherer, T. Mölg, E. Collier, J. Curio, and R. Finkelnburg, 2014: Precipitation seasonality and variability over the Tibetan Plateau as resolved by the High Asia Reanalysis. J. Climate, 27, 1910-1927, https://doi.org/10.1175/ JCLI-D-13-00282.1.

McDowell, G., J. D. Ford, B. Lehner, L. Berrang-Ford, and A. Sherpa, 2013: Climate-related hydrological change and human vulnerability in remote mountain regions: A case study from Khumbu, Nepal. Reg. Environ. Change, 13, 299-310, https://doi.org/10.1007/s10113-012-0333-2.

Ménégoz, M., H. Gallée, and H. Jacobi, 2013: Precipitation and snow cover in the Himalaya: from reanalysis to regional climate simulations. Hydrol. Earth Syst. Sci., 17, 3921-3936, https://doi.org/10.5194/hess-17-3921-2013.

Mimeau, L., M. Esteves, I. Zin, H.-W. Jacobi, F. Brun, P. Wagnon, and Y. Arnaud, 2018: Quantification of different flow components in a high-altitude glacierized catchment (Dudh Koshi, Nepalese Himalaya). Hydrol. Earth Syst. Sci. Discuss., https:// doi.org/10.5194/hess-2018-34.

Nash, J. E., and J. V. Sutcliffe, 1970: River flow forecasting through conceptual models part I-A discussion of principles. J. Hydrol., 10, 282-290, https://doi.org/10.1016/0022-1694(70)90255-6.

Naz, B. S., C. Frans, G. Clarke, P. Burns, and D. Lettenmaier, 2014: Modeling the effect of glacier recession on streamflow response using a coupled glacio-hydrological model. Hydrol. Earth Syst. Sci., 18, 787-802, https://doi.org/10.5194/hess-18-787-2014.

Nuimura, T., and Coauthors, 2015: The GAMDAM glacier inventory: A quality-controlled inventory of Asian glaciers. Cryosphere, 9, 849-864, https://doi.org/10.5194/tc-9-849-2015.

Palazzi, E., J. Hardenberg, and A. Provenzale, 2013: Precipitation in the Hindu-Kush Karakoram Himalaya: Observations and future scenarios. J. Geophys. Res. Atmos., 118, 85-100, https:// doi.org/10.1029/2012JD018697.

Pritchard, H. D., 2017: Asia's glaciers are a regionally important buffer against drought. Nature, 545, 169-174, https://doi.org/ 10.1038/nature22062.

Ragettli, S., and Coauthors, 2015: Unraveling the hydrology of a Himalayan catchment through integration of high resolution in situ data and remote sensing with an advanced simulation model. Adv. Water Resour., 78, 94-111, https://doi.org/ 10.1016/j.advwatres.2015.01.013.

Rienecker, M. M., and Coauthors, 2011: MERRA: NASA's modern-era retrospective analysis for research and applications. J. Climate, 24, 3624-3648, https://doi.org/10.1175/ JCLI-D-11-00015.1.

Salerno, F., and Coauthors, 2015: Weak precipitation, warm winters and springs impact glaciers of south slopes of Mt. Everest (central Himalaya) in the last 2 decades (19942013). Cryosphere, 9, 1229-1247, https://doi.org/10.5194/ tc-9-1229-2015.

Savéan, M., F. Delclaux, P. Chevallier, P. Wagnon, N. GongaSaholiariliva, R. Sharma, L. Neppel, and Y. Arnaud, 2015: Water budget on the Dudh Koshi River (Nepal): uncertainties on precipitation. J. Hydrol., 531, 850-862, https://doi.org/ 10.1016/j.jhydrol.2015.10.040.

Scherler, D., B. Bookhagen, and M. R. Strecker, 2011: Spatially variable response of Himalayan glaciers to climate change 
affected by debris cover. Nat. Geosci., 4, 156-159, https:// doi.org/10.1038/ngeo1068.

Shea, J., W. Immerzeel, P. Wagnon, C. Vincent, and S. Bajracharya, 2015: Modelling glacier change in the Everest region, Nepal Himalaya. Cryosphere, 9, 1105-1128, https://doi.org/10.5194/ tc-9-1105-2015.

Shrestha, A. B., and R. Aryal, 2011: Climate change in Nepal and its impact on Himalayan glaciers. Reg. Environ. Change, 11, 65-77, https://doi.org/10.1007/s10113-010-0174-9.

Singh, S., R. Kumar, A. Bhardwaj, L. Sam, M. Shekhar, A. Singh, R. Kumar, and A. Gupta, 2016: Changing climate and glaciohydrology in Indian Himalayan region: A review. Wiley Interdiscip. Rev.: Climate Change, 7, 393-410, https://doi.org/10.1002/wcc.393.

Sirguey, P., R. Mathieu, and Y. Arnaud, 2009: Subpixel monitoring of the seasonal snow cover with MODIS at $250 \mathrm{~m}$ spatial resolution in the Southern Alps of New Zealand: Methodology and accuracy assessment. Remote Sens. Environ., 113, 160181, https://doi.org/10.1016/j.rse.2008.09.008.

Soncini, A., and Coauthors, 2016: Future hydrological regimes and glacier cover in the Everest region: The case study of the upper Dudh Koshi basin. Sci. Total Environ., 565, 1084-1101, https:// doi.org/10.1016/j.scitotenv.2016.05.138.

Thériault, J. M., R. Rasmussen, K. Ikeda, and S. Landolt, 2012: Dependence of snow gauge collection efficiency on snowflake characteristics. J. Appl. Meteor. Climatol, 51, 745-762, https:// doi.org/10.1175/JAMC-D-11-0116.1.
Uppala, S. M., and Coauthors, 2005: The ERA-40 re-analysis. Quart. J. Roy. Meteor. Soc., 131, 2961-3012, https://doi.org/ 10.1256/qj.04.176.

Viviroli, D., H. H. Dürr, B. Messerli, M. Meybeck, and R. Weingartner, 2007: Mountains of the world, water towers for humanity: Typology, mapping, and global significance. Water Resour. Res., 43, W07447, https:// doi.org/10.1029/2006WR005653.

Wagnon, P., and Coauthors, 2013: Seasonal and annual mass balances of Mera and Pokalde glaciers (Nepal Himalaya) since 2007. Cryosphere, 7, 1769-1786, https://doi.org/10.5194/tc-71769-2013.

Wang, B., 2006: The Asian Monsoon. Springer, 845 pp.

Wigmosta, M. S., L. W. Vail, and D. P. Lettenmaier, 1994: A distributed hydrology-vegetation model for complex terrain. Water Resour. Res., 30, 1665-1679, https://doi.org/10.1029/ 94WR00436.

Wolff, M., K. Isaksen, A. Petersen-Øverleir, K. Ødemark, T. Reitan, and R. Brækkan, 2015: Derivation of a new continuous adjustment function for correcting wind-induced loss of solid precipitation: Results of a Norwegian field study. Hydrol. Earth Syst. Sci., 19, 951-967, https://doi.org/10.5194/ hess-19-951-2015.

Yatagai, A., K. Kamiguchi, O. Arakawa, A. Hamada, N. Yasutomi, and A. Kitoh, 2012: APHRODITE: Constructing a long-term daily gridded precipitation dataset for Asia based on a dense network of rain gauges. Bull. Amer. Meteor. Soc., 93, 14011415, https://doi.org/10.1175/BAMS-D-11-00122.1. 